\title{
Influence of size and surface capping on photoluminescence and cytotoxicity of gold nanoparticles
}

\author{
Cecilia Fernández-Ponce • Juan P. Muñoz-Miranda • \\ Desiré M. de los Santos • Enrique Aguado • \\ Francisco García-Cozar • Rocío Litrán $(\mathbb{D}$
}

Received: 10 May 2018 / Accepted: 24 October 2018 / Published online: 15 November 2018

(C) The Author(s) 2018

\begin{abstract}
Hydrophilic and homogeneous sub-10 nm blue light-emitting gold nanoparticles (NPs) functionalized with different capping agents have been prepared by simple chemical routes. Structure, average, size, and surface characteristics of these NPs have been widely studied, and the stability of colloidal NP solutions at different $\mathrm{pH}$ values has been evaluated. Au NPs show blue PL emission, particularly in the GSH capped NPs, in which the thiol-metal core transference transitions considerably enhance the fluorescent emission. The influence of capping agent and NP size on cytotoxicity and on the fluorescent emission are analyzed and discussed in order to obtain Au NPs with suitable features for biomedical applications. Cytotoxicity of different types of gold NPs has been determined using NPs at high concentrations in both tumor cell lines and primary cells. All NPs used show high biocompatibility with low cytotoxicity even at high concentration, while Au-GSH
\end{abstract}

Electronic supplementary material The online version of this article (https://doi.org/10.1007/s11051-018-4406-0) contains supplementary material, which is available to authorized users.

C. Fernández-Ponce · J. P. Muñoz-Miranda · E. Aguado • F. García-Cozar

Department of Biomedicine, Biotechnology and Public Health, University of Cadiz, Cádiz, Spain

C. Fernández-Ponce · J. P. Muñoz-Miranda · E. Aguado • F. García-Cozar · R. Litrán Institute of Biomedical Research Cádiz (INIBICA), Cádiz, Spain
NPs decrease viability and proliferation of both a tumor cell line and primary lymphocytes.

Keywords Gold nanoparticles · Cytotoxicity · Cell viability Proliferation Photoluminescence - Capping · Agent $\cdot$ GSH $\cdot$ Semiconfocal microscopy

\section{Introduction}

Gold nanoparticles (Au NPs) are interesting nanomaterials used in a wide variety of technologies, including catalysis (Peng et al. 2017; Wei et al. 2018; Zhu et al. 2010), nanoelectronics (Bafrani et al. 2018; Barman and Verma 2010; Dong et al. 2017; Huang et al. 2018; Jain et al. 2008; Kamyshny and Magdassi 2014), and biomedicine (Dreaden et al. 2012; Giljohann et al. 2010; Huang et al. 2009; Jain et al. 2008; Khan et al. 2018).

D. M. de los Santos

Department of Physical Chemistry and Instituto de Microscopía Electronica y Materiales (IMEYMAT), University of Cádiz,

Cádiz, Puerto Real, Spain

R. Litrán $(\bowtie)$

Department of Condensed Matter Physics and Instituto de

Microscopía Electronica y Materiales (IMEYMAT)

University of Cádiz,

Cádiz, Puerto Real, Spain

e-mail: rocio.litran@uca.es 
Over the last two decades, Au NPs have been mainly used as biosensors and as contrast agents in X-ray imaging and computed tomography (Kobayashi et al. 2016), being applied in biological and biomedical research, especially in cancer diagnosis (Chuang et al. 2018; Kim et al. 2018; Sugumaran et al. 2018) and therapy (Khandanlou et al. 2018; Zhu et al. 2018), biosensing (Baetsen-Young et al. 2018; Chen et al. 2009), virus detection, and regulation of cell function (Bodelon et al. 2017; Giljohann et al. 2010).

The biomedical interest of these NPs resides in their good biocompatibility, low inherent toxicity (Lewinski et al. 2008), facile synthesis (Jain et al. 2006), high biofunctionalization capability ( $\mathrm{Li}$ et al. 2018), and especially, in their unique optical properties.

The so-called localized surface plasmon resonance (LSPR) (Hu et al. 2006) is a phenomenon that can be described as the collective coherent oscillation of conduction electrons with respect to a positive metallic lattice, occurring when small metallic NPs are stimulated by the electromagnetic field of incident light (Hutter and Fendler 2004). Consequently, these metallic NPs show a high absorption cross section in the visible-NIR range, making them appropriate agents for bioimaging and even for treatment by hyperthermia (Ghosh et al. 2008; Huang et al. 2009). In the case of gold, the LSPR band is located around $500-540 \mathrm{~nm}$ for NPs with sizes smaller than $30 \mathrm{~nm}$. However, the LSPR band position is affected by size, shape, interparticle distance, and dielectric constant, as well as the refractive index of surrounding media, which can shift the LSPR, even to the NIR range (Haes et al. 2004; Jain et al. 2007; Sugumaran et al. 2018).

Absorption is not the only optical property that can make these NPs useful in bioimaging. Recently, photoluminescence (PL) of gold NPs has attracted considerable attention, due to their potential applications (Liu et al. 2014). Interband radiative recombination of electrons in noble metals was first reported by Mooradian in 1969 (Mooradian 1969), while Wilcoxon in 1998 observed a PL band around $440 \mathrm{~nm}$ in small gold clusters and proposed a mechanism for luminescence in Au nanoparticles (Wilcoxon et al. 1998). Afterwards, other groups have reported tunable emissions, from UV to NIR in gold NPs (Chen et al. 2009). The emission of these NPs is usually assigned to the interband transition $\mathrm{Au} 5 \mathrm{~d}^{10}$ to $6 \mathrm{sp}$ and also to the capping ligand-metal charge transfer transition. Other authors have reported the influence of size and NP surface in the PL emission (Liu et al. 2014).
Functionalization of the NP surface with species containing bio-active terminal groups, such as amino or carboxylic groups, allows for a subsequent linking with relevant biomolecules (Albanese et al. 2012; Miao et al. 2018). NP functionalization can also contribute to avoiding aggregation and unspecific cellular uptake, minimizing accumulation in organs and/or phagocyte activation, thus maintaining a prolonged circulation time (Nel et al. 2009; Silvestri et al. 2017; Sperling and Parak 2010; Verma and Stellacci 2010). For biomedical applications, surface functionalization is a common strategy not only to subsequently promote cross-linking between NPs and specific biological species but also to minimize their cytotoxicity and unspecific binding.

Preparation methods that allow for a direct functionalization such as "Bottom-up" methods are the most common strategies for the preparation of monodispersed Au NPs (Huang et al. 2009). The first chemical synthesis route to prepare Au NPs was the Turkevich method (Turkevich et al. 1951), a reducing reaction that uses sodium citrate as reducing agent. This method has been modified for many different authors in order to increase the monodispersity of the resulting NPs (Piella et al. 2016; Zhao et al. 2012). Many other authors have reported on gold NPs prepared by reduction in the presence of a capping ligand that directly biofunctionalize the NP or facilitate its subsequent biofunctionalization (Fratoddi 2018), controlling the particle growth. This route also allows for the use of thiols as capping agents, due to the high affinity of this group for the gold surface (Brust et al. 1994; Dehn et al. 2018).

In this work, we have synthesized four different types of $\mathrm{Au} \mathrm{NPs}$, based either on a modification of the Turkevich method or on a reduction using sodium borohydride as reductor and thiols as capping agents. For the citrate-based method, we have used variations of the traditional Turkevich route as well as a "seeded-growth" method, introducing simplifications on the Piella et al. route (Piella et al. 2016). For the reduction with sodium borohydride, we used either cysteamine $\left(\mathrm{C}_{2} \mathrm{H}_{7} \mathrm{NS}\right.$ (CYS)) (Niidome et al. 2004) or glutathione $\left(\mathrm{C}_{10} \mathrm{H}_{17} \mathrm{~N}_{3} \mathrm{O}_{6} \mathrm{~S}(\mathrm{GSH})\right.$ ) (Beato-Lopez et al. 2017; Beato-Lopez et al. 2012) as capping agents. Both capping agents contain a thiol group to be linked to the NP surface, as well as an amino terminal group (in the case of CYS) or both amino and carboxylic groups (in the case of GSH), that remain free to be cross-linked with other biomolecules, as we have previously shown (Beato-Lopez et al. 2017). Thus, starting from different 
synthetic routes, we obtain NPs with different capping, size, and homogeneity (Albanese et al. 2012; Chithrani et al. 2006; Li et al. 2018; Silvestri et al. 2017; Verma and Stellacci 2010).

We have analyzed size average, homogeneity, and structural characteristics of the obtained Au NPs. We have obtained four different capped gold NPs with average sizes ranging from 3 to $10 \mathrm{~nm}$, which is important for biomedical applications, as many body barriers fall in the sub-10 $\mathrm{nm}$ range, while an increase in toxicity has been shown for NPs smaller than $2 \mathrm{~nm}$ (Khan et al. 2018; Lewinski et al. 2008; Pan et al. 2007; Sukhanova et al. 2018; Wozniak et al. 2017).

We have also studied NP surface characteristics and their colloidal behavior, as well as their stability at different $\mathrm{pH}$ values, particularly in the physiological $\mathrm{pH}$ range.

As the objective of these synthesis is to obtain functionalized gold NPs useful for biomedical applications, we have also studied their optical properties: optical absorption and photoluminescence, in order to analyze the interest of these NPs as bioimaging agents. We have studied the influence of NP size and capping on the LSPR band and on their PL emission, in order to evaluate NPs with potential for biomedical applications and analyzed the cytotoxicity of NPs, not only in transformed cell lines but also in primary cells, to closely mirror the situation in clinical settings.

Our purpose is to obtain biocompatible functionalized Au NPs and to study the influence of functionalization on their optical properties, stability, and cytotoxicity. Functionalization is a key and common factor for all biomedical applications, such as X-ray imaging and biosensing, and although the PL intensity of these Au NPs is not comparable to that of conventional biomarkers, their higher biocompatibility may facilitate their introduction in clinical settings where their emission intensity is enough and additionally PL characteristics can be an asset for the follow-up and complementation of any other application.

\section{Experimental}

\section{Chemicals}

Tetrachloroauric acid $\left(\mathrm{HAuCl}_{4}\right)$, sodium citrate $\left(\mathrm{Na}_{3} \mathrm{C}_{6} \mathrm{H}_{5} \mathrm{O}_{7}\right)$, tannic acid $\left(\mathrm{C}_{76} \mathrm{H}_{52} \mathrm{O}_{46}\right)$, sodium borohydride $\left(\mathrm{NaBH}_{4}\right)$, cysteamine $\left(\mathrm{C}_{2} \mathrm{H}_{7} \mathrm{NS}\right)$, and reduced glutathione $\left(\mathrm{C}_{10} \mathrm{H}_{17} \mathrm{~N}_{3} \mathrm{O}_{6} \mathrm{~S}\right)$ were purchased from Sigma-Aldrich and used as received. All the chemicals were of analytic grade, and Milli-Q water was used for all experiments.

\section{Au NPs preparation}

Four different types of gold NPs were synthesized starting from the reduction of $\mathrm{Au}^{3+}$ cations present in the $\mathrm{HAuCl}_{4}$. Two different reducing agents were used: sodium citrate for synthesis A and B, and sodium borohydride for synthesis C and D.

\section{Synthesis A: method based on the traditional Turkevich} reaction

Briefly, $20 \mathrm{~mL}$ of a $0.01 \mathrm{M} \mathrm{HAuCl}_{4}$ aqueous solution was heated until $97^{\circ} \mathrm{C}$ with vigorous stirring. Once this temperature was reached, $2 \mathrm{~mL}$ of a sodium citrate aqueous solution was added, in a $\mathrm{HAuCl}_{4} / \mathrm{Na}_{3} \mathrm{C}_{6} \mathrm{H}_{5} \mathrm{O}_{7}$ molar ratio of 1:5. After $10 \mathrm{~min}$ of strong stirring, the solution was stored at $8{ }^{\circ} \mathrm{C}$ in the protected from light.

A schematic representation of NPs obtained from this method is shown in Fig. 1a. We represent a spherical gold core surrounded by citrate ligands. Even if the precise structure of capped NP can be much more complex, this schematics allows us to have a graphical representation of the system. The code $\mathrm{Au}-\mathrm{C}$ is used for this type of NPs.

\section{Synthesis B: seeded-growth method}

This synthesis is also based on the reduction of $\mathrm{HAuCl}_{4}$ using sodium citrate, but including the addition of a co-reducing agent, in order to promote the fast nucleation and successive growth in order to homogenize NP size. The process is based on that proposed by Piella et al. (Piella et al. 2016) but introducing some simplifications.

We have used a 1:10, $\mathrm{HAuCl}_{4} / \mathrm{Na}_{3} \mathrm{C}_{6} \mathrm{H}_{5} \mathrm{O}_{7}$ molar ratio. A co-reducing agent, the tannic acid, is used to promote gold nucleation. The reaction occurs in the following steps: In the first step, $1 \mathrm{~mL}$ of $\mathrm{HAuCl}_{4}$ $0.025 \mathrm{M}$ was added to a three-necked round-button flask containing a mixture of $150 \mathrm{~mL} 2.2 \mathrm{mM}$ sodium citrate and $0.1 \mathrm{~mL} 2.5 \mathrm{mM}$ tannic acid, previously heated at $70{ }^{\circ} \mathrm{C}$. In a few minutes, a brownish-orange color was observed, indicating formation of small gold nuclei. After 5 and $20 \mathrm{~min}, 55 \mathrm{~mL}$ of the solution was drawn 


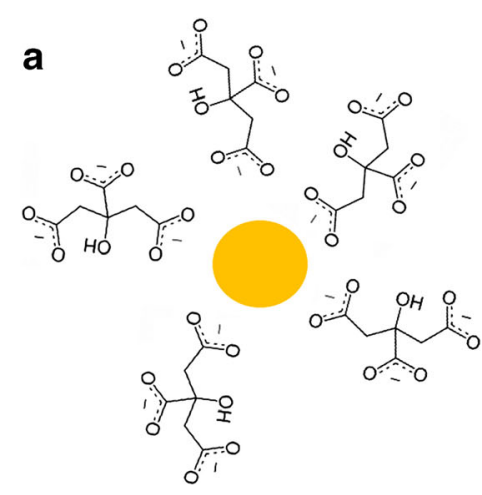

Fig. 1 Schematic representation of different Au NP capping agents. a NP obtained by synthesis A or B (named $\mathrm{Au}-\mathrm{C}$ and $\mathrm{Au}-\mathrm{TC}$, respectively): spherical gold core surrounded by citrate ligands. b NP obtained by synthesis $\mathrm{C}$ (named Au-CYS): the gold

from the flask and $0.5 \mathrm{~mL} 0.025 \mathrm{M} \mathrm{HAuCl}_{4}$ and $55 \mathrm{~mL}$ $2.2 \mathrm{mM}$ citrate solution were added to the reaction. The reaction continued for 20 more minutes before the final solution was cooled and stored at $8{ }^{\circ} \mathrm{C}$ in the dark. These two last steps were carried out to complete the homogenous growing of the seeds formed in the initial step.

As in the case of synthesis A, the final gold core obtained by this process must be surrounded by citrate ligands, added in excess in the three steps of the reaction (see schematics in Fig. 1a). The code Au-TC is used for this type of NPs in order to distinguish them from the ones obtained with the same capping but from synthesis A.

\section{Synthesis C: CYS capped Au NPs}

The reaction is based in the reduction of $\mathrm{HAuCl}_{4}$ in aqueous media using $\mathrm{NaBH}_{4}$ as reducing agent and cysteamine (CYS) as capping agent to control the growth and to avoid aggregation (Niidome et al. 2004). We have modified previous methods to decrease and homogenize the average size of NPs.

Forty milliliters of a $0.01 \mathrm{M} \mathrm{HAuCl}_{4}$ aqueous solution was mixed with $1 \mathrm{~mL}$ of a $0.08 \mathrm{M}$ CYS aqueous solution. The mixture was vigorously stirred for 30 min under a nitrogen atmosphere. Subsequently, an aqueous solution of $\mathrm{NaBH}_{4}$ was added dropwise, in a 1:0.5 $\mathrm{HAuCl}_{4} / \mathrm{NaBH}_{4}$ molar ratio. After 30 additional minutes, the red wine color solution was kept at $8{ }^{\circ} \mathrm{C}$ in the dark. A schematic representation of the final NP obtained by synthesis $\mathrm{C}$ is shown in Fig. 1b. The gold core can link to the thiol groups on the CYS molecule. The code AuCYS is used for this type of NPs.

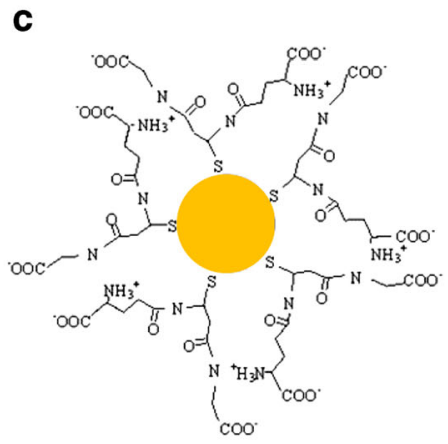

core can link to the thiol groups on the CYS molecule. c NP obtained by synthesis D (named Au-GSH): the gold core is bound to GSH thiol groups

\section{Synthesis D: GSH capped Au NPS}

In this case, the reduction also takes place using $\mathrm{NaBH}_{4}$ in aqueous media. However, in this case, GSH was used as capping agent.

Briefly, $10 \mathrm{~mL} 0.01 \mathrm{M} \mathrm{HAuCl}_{4}$ aqueous solution was mixed with $10 \mathrm{~mL} 0.026 \mathrm{M} \mathrm{GSH}$ aqueous solution. The mixture was vigorously stirred for 30 min under a nitrogen atmosphere. $\mathrm{A} \mathrm{NaBH}_{4}$ aqueous solution was added dropwise, in a 1:5 $\mathrm{HAuCl}_{4} / \mathrm{NaBH}_{4}$ molar ratio. After 30 additional minutes, the red wine color solution was stored at $8{ }^{\circ} \mathrm{C}$ protected from light. Based on our previous works (Beato-Lopez et al. 2017; Beato-Lopez et al. 2012), we have designed this rapid route to obtained small GSH capped gold NPs. Figure 1c shows a schematic representation of the final NP obtained by this synthesis. The gold core is bound to GSH thiol groups. The code Au-GSH is used for this type of NPs.

\section{Characterization}

Structural studies as well as particle average size estimations have been obtained from transmission electron microscopy, using a FEI Nova NanoSEM 450, operating at STEM (scanning transmission electron microscopy) mode. Samples were prepared by depositing $10 \mu \mathrm{L}$ of an Au NP colloidal solution that was drop-casted onto a holey-carbon-coated $\mathrm{Cu}$ grid and dried for $5 \mathrm{~h}$. Images were obtained either in dark field (DF) or bright field (BF). High-resolution images have been obtained transmission electron microscopy (TEM) using a JEOL 2010.

Dynamic light scattering (DLS) was used to measure the hydrodynamic NP size. Measurements were carried 
out at $25^{\circ} \mathrm{C}$, using a Nanotrac Wave (Microtrac) equipment, with a $0.5 \mathrm{~cm}$ path cell. This equipment also allows for the $Z$ potential to be measured which evaluates colloidal solution stability, as well as NP surface charge.

The study of gold nanoparticles functionalized with different capping agents was analyzed by Fourier transformed infrared spectrophotometry (FTIR). The spectra were recorded in the region 4000 to $400 \mathrm{~cm}^{-1}$ by means of a Bruker Tensor 37 spectrophotometer.

$\mathrm{Au}$ NP LSPR has been evaluated studying the UVVis absorbance of each NP colloidal solution. Absorption spectra were acquired with a Lambda 19 PerkinElmer spectrophotometer. Position and profile of LSPR band provide information about NP dispersion and allow for the estimation of NP average size.

Photoluminescence excitation and emission spectra have been recorded in a PTI Quantamaster fluorometer using a Xenon arc Lamp at $150 \mathrm{~W}$ and a computer controller QuadraScopic monochromator. Fluorescence lifetime measurements have been made by means of a LaserStrobe technique by using a nitrogen/dye laser GL-3300 providing $440 \mathrm{~kW}$ peak power at $5 \mathrm{~Hz}$ with a pulse width of $1 \mathrm{~ns}\left(1.68 \mathrm{~mJ} /\right.$ pulse for $\left.\mathrm{N}_{2}\right)$. The $\mathrm{N}_{2}$ laser optical pulse and the timing electronics of LaserStrobe, which scans different time delays after pulse, allow for a temporal resolution of up to $100 \mathrm{ps}$.

\section{Cell culture}

Primary cells were obtained from human peripheral blood samples from healthy donors upon signature of an informed consent and following approval by the Ethics Committee of the Puerta del Mar University Hospital, according to Spanish and European regulations. Peripheral blood mononuclear cells (PBMC) were isolated by density gradient centrifugation using lymphocyte separation media (Eurobio ${ }^{\mathrm{TM}}$, Montpellier, France). PBMC were stimulated with $1 \mu \mathrm{g} / \mathrm{mL}$ phytohemagglutinin-P (PHA) (Sigma $^{\mathrm{TM}}$, Saint Louis, $\mathrm{MO}$, USA) and cultured at $37{ }^{\circ} \mathrm{C}$ in a $5 \% \mathrm{CO}_{2}$ atmosphere in Dulbecco's modified Eagle's medium (DMEM) containing $2 \mathrm{mM} \mathrm{L-glutamine,} 10 \mathrm{mM}$ HEPES, $10 \%(v / v)$ heat-inactivated fetal bovine serum (FBS), $1 \%(v / v)$ non-essential amino acids (NEAA), $1 \%$ $(v / v)$ sodium pyruvate, $50 \mu \mathrm{M} 2$-mercaptoethanol, $100 \mathrm{U} / \mathrm{mL}$ penicillin, and $100 \mu \mathrm{g} / \mathrm{mL}$ streptomycin (all from Life Technologies, Carlsbad, CA, USA). Forty units per milliliter IL-2 was added to the culture every
$48 \mathrm{~h}$ for a total of 6 days before the experiment. CD3, CD4, and CD8 expression in PBMC blasts the day of the experiment ranged from 77.8 to $65 \%$ for $\mathrm{CD} 3 \%$, 65.3 to $49.3 \%$ for CD4, and 12.5 to $15.7 \%$ for CD8. Jurkat cells (American Type Culture Collection, Manassas, VA, USA) were cultured in the same conditions as $\mathrm{PBMC}$, and CD3 expression was evaluated periodically and always found to be above $80 \%$ (in supplementary Fig. S.1, we show flow cytometry data of blood, PBMC, and Jurkat cells from a representative experiment).

Cell viability, cytotoxicity, and proliferation assays

For both primary as well as Jurkat cells, $5 \times 10^{5}$ cells were cultured in a 24-well plate, in the absence or presence of nanoparticles at $1.5 \mu \mathrm{g} / \mathrm{mL}$ or $15 \mu \mathrm{g} / \mathrm{mL}$.

Cell viability was analyzed at $24 \mathrm{~h}$ after addition of NPs by an MTT-based assay as previously described (Vistica et al. 1991). Briefly, MTT reactant (Thiazolyl Blue Tetrazolium Bromide, TOX1-1KT, Sigma-A1drich) was added to the cells in a 1:10 ratio (MTT solution/culture medium) and incubated during $2 \mathrm{~h}$ at $37^{\circ} \mathrm{C}$. Then, formazan crystals formed inside the cells were dissolved by adding MTT Solubilization Solution (M-8910, Sigma-Aldrich) at 1:2 with vigorous pipetting. Optical density at $570 \mathrm{~nm}$ was evaluated to quantify the amount of formazan crystals, which is proportional to the number of viable cells (background absorbance was measured at $690 \mathrm{~nm}$ and subtracted from the $570 \mathrm{~nm}$ measurement). Viability was compared to untreated controls $(100 \%)$.

Cell cytotoxicity assay Cells were cultured as for the viability assay and after $24 \mathrm{~h}$, were harvested, and cell death was evaluated by staining with a live/dead fixable near-IR dead cell stain kit (Thermo Fisher Scientific ${ }^{\text {TM}}$ ) and analyzed in a Cytoflex ${ }^{\mathrm{TM}}$ Flow cytometer (Beckman Coulter, Inc., Fullerton, CA).

Cell proliferation assay To label dividing cells, $10 \mu \mathrm{M}$ EdU was added to the cultures for $24 \mathrm{~h}$ in the presence or absence of the corresponding nanoparticles. Cells were subsequently harvested, fixed in the Click-iТтм fixative, and permeabilized with a saponin-based permeabilization and wash reagent (Click-iT ${ }^{\mathrm{TM}}$ EdU Pacific Blue $^{\mathrm{TM}}$, Thermo Fisher Scientific $\left.{ }^{\mathrm{TM}}\right)$. Edu was bound to a Pacific blue dye by means of a click reaction for 30 min (Breinbauer and Kohn 2003), washed twice with a saponin-based permeabilization and wash reagent, and 
analyzed in a Cytoflex ${ }^{\mathrm{TM}}$ flow cytometer (Beckman Coulter).

\section{Optical microscopy}

Jurkat cells $1 \times 10^{5}$ per well in $200 \mu \mathrm{L}$ (at $5 \times 10^{5}$ cells $/ \mathrm{mL}$ ) were cultured without nanoparticles or in the presence of nanoparticles at $1.5 \mu \mathrm{g} / \mathrm{mL}$ or $15 \mu \mathrm{g} /$ $\mathrm{mL}$, subsequently washed with phosphate-buffered saline (PBS), and fixed in a solution containing 4\% formaldehyde in PBS at room temperature, for $30 \mathrm{~min}$. After an additional washing step, cells were centrifuged at $900 \mathrm{rpm}$ for $5 \mathrm{~min}$ on adhesion polylysine slides, Polysine® VWR Collection by means of a Cytospin ${ }^{\mathrm{TM}} 4$ Cytocentrifuge (ThermoFisher Scientific), washed and mounted with Fluoro-Gel mounting medium (Catalog \#17985-10, Electron Microscopy Sciences). Slides were analyzed on an Olympus Confocal microscope. Cells were excited at $\lambda 405$, and emission was collected at $\lambda 413-510$ with a $\times 40$ magnification. Images were analyzed with the Fiji distribution software (Schindelin et al. 2012) of Image J (Schneider et al. 2012). Percentage of blue (413-510 $\lambda$ )-emitting cells from total cell (from a transmission micrograph) were obtained from three independent experiments and analyzed by one-way ANOVA using the XLSTAT ${ }^{\circledR}$ Excell® plug in.

\section{Results and discussion}

\section{Structural and chemical features}

TEM micrographs of the obtained gold NPs reveal the formation of relatively small and well-dispersed NPs with homogeneous size distributions and without aggregation (Fig. 2a-e show a general view for the different $\mathrm{Au}$ NPs). Insets show histograms for each type of NP, showing the size distribution obtained from the analysis of more than 300 NPs like those shown in micrographs. NP average sizes obtained from the fitting of these histograms to a Gaussian function are shown in Table 1. Au-C NPs prepared by synthesis A (classical sodium citrate synthesis) show a wider average size, with two main average sizes centered at 7.5 and $14.5 \mathrm{~nm}$, respectively. Size distribution for these NPs shows a bimodal profile, indicating either the inhomogeneous growth or the aggregation of gold cores. Figure $2 b$ shows the micrograph corresponding to Au-TC NPs after 5 min of synthesis (for this measurement, an aliquot of the colloidal solution was drawn $5 \mathrm{~min}$ after starting the reaction). We can observe formation of gold cores of an average size of $3.5 \mathrm{~nm}$, with a homogeneous size distribution. The use of a strong co-reducing agent (tannic acid) promotes rapid nucleation and a consequent formation of small nuclei. At this point, the reaction is in the initial phase and the rate of nuclei production is faster than the rate of Ostwald ripening, leading to small NPs. After completion of the synthesis (45 min, Fig. 2c), $\mathrm{Au}$-TC NPs reach an average size of $7.0 \mathrm{~nm}$ with a low size dispersion. As the reaction progresses, the rate of Ostwald ripening takes over and we have slightly bigger sizes. In this case, modifications included in the classical Turkevich route lead to homogenization of NP sizes. Rapid formation of gold nuclei in the first step of the reaction allows for a homogeneous growth yielding NPs with high monodispersity.

Thiol capped NPs (Fig. 2d, e) show average sizes of $6.5 \mathrm{~nm}$ and $3.5 \mathrm{~nm}$ for Au-CYS and Au-GSH, respectively (Table 1). Au-CYs NPs (Fig. 2d) show an average size of $6.5 \mathrm{~nm}$, a diameter similar to that obtained for $\mathrm{Au}-\mathrm{TC}$. However, high-resolution images for these two types of NPs (Fig. 2f, g) show a more homogeneous distribution for $\mathrm{Au}$-TC.

Au-GSH NPs (Fig. 2e) show a particularly small size distribution. We have previously reported production of small GSH capped NPs by means of a high GSH/Au molar ratio. The average size of this type of NPs is similar to that of Au-TC after a 5-min reaction (Fig. 2b); however, size distribution for Au-GSH NPs is considerably wider. Indeed, even though the micrograph corresponding to Au-GSH (Fig. 2e) shows a majority of small NP, NPs with sizes higher than the average value are also present.

Summarizing these results, we have obtained Au NPs with average sizes from 3.5 to $7 \mathrm{~nm}$. When we use the seeded-growth method, we obtained slightly higher monodispersity than when we directly capped using thiol ligands. However, thiol capped Au NPs have the advantage of being directly functionalized for biomedical applications.

In order to compare TEM diameters with hydrodynamic sizes for NPs in solution, DLS experiments were performed. Average sizes obtained from these measurements are shown in Table 1. The general good agreement between TEM and DLS diameters indicates the absence of NP aggregation in the water colloid, and 

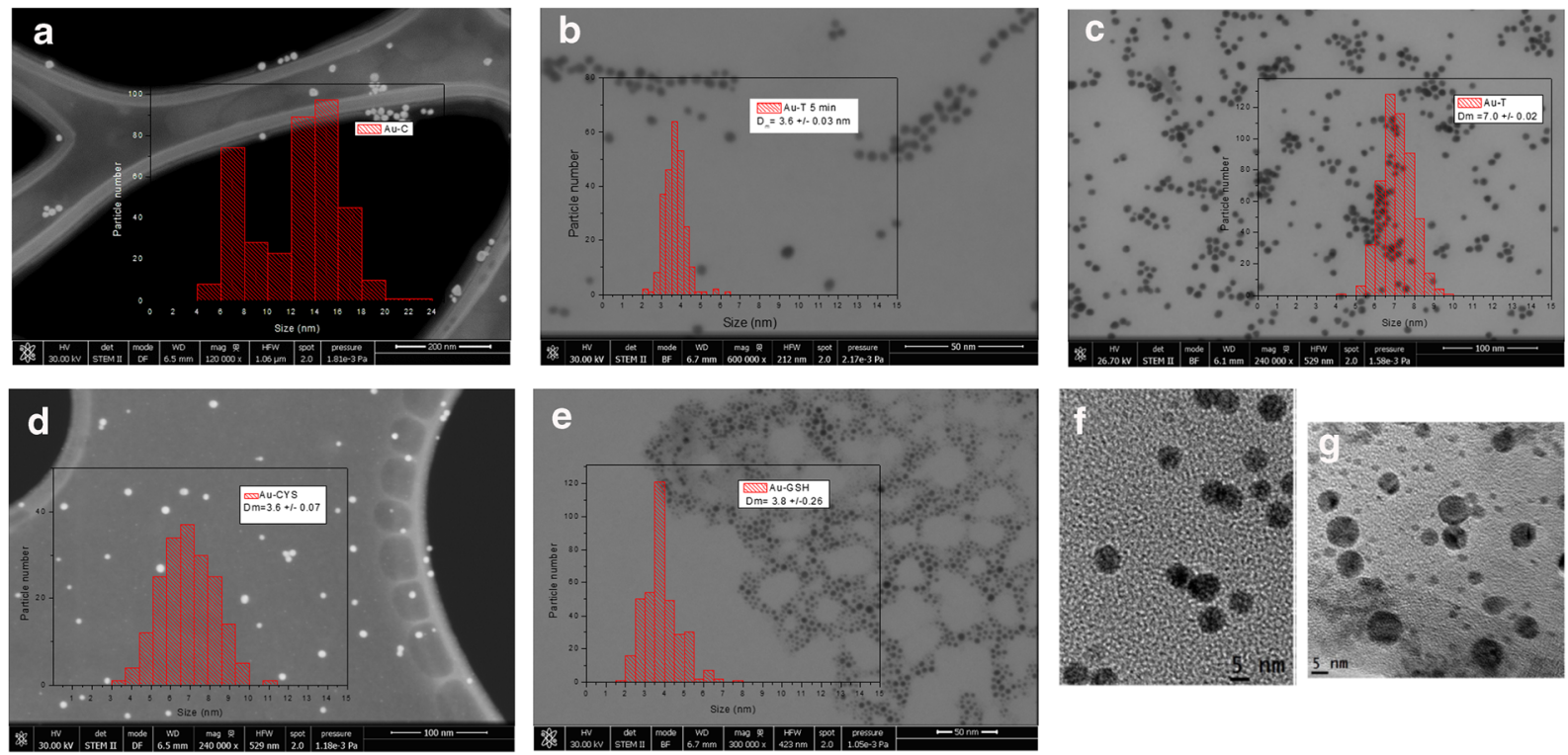

Fig. 2 TEM micrographs obtained from different Au NP capping agents: a Au-C, b Au-TC after 5 min of synthesis, c Au-TC after 45 min of synthesis, d Au-CYS, e Au-GSH. Corresponding

consequently, a well-established Au NP colloidal systems. However, DLS sizes should show the effect of capping on the hydrodynamic sphere. Interestingly, we only find this effect in Au-CYS. DLS size distribution for Au-CYS (supplementary Fig. S.2.a) shows an average size of $8 \mathrm{~nm}$, slightly bigger than the TEM diameter for this NP. In this case, the differences between DLS and TEM diameters could be due to the effect of CYS capping on the hydrodynamic diameter. Figure S.2.b in the supplementary material shows the DLS distribution for $\mathrm{Au}$-TC NPs. In this case, there are no significative differences between DLS and TEM average sizes. However, comparing TEM and DLS distribution for this sample (Figs. 2c and S.2.b), we can appreciate that DLS distribution shows a higher portion of NPs with

Table 1 TEM and DLS size estimates and values for $Z$ potential for each NP type

\begin{tabular}{lclc}
\hline NP code & TEM size $(\mathrm{nm})$ & DLS size $(\mathrm{nm})$ & $Z$ potential $(\mathrm{mV})$ \\
\hline Au-C & $14.5 \pm 0.28$ & $4.9 \pm 0.1$ & -158 \\
Au-TC & $7.0 \pm 0.02$ & $6.9 \pm 0.4$ & -99 \\
Au-CYS & $6.5 \pm 0.07$ & $8.0 \pm 0.1$ & +88 \\
Au-GSH & $3.8 \pm 0.26$ & $3.6 \pm 0.2$ & -140 \\
Au-TC 5 min & $3.6 \pm 0.03$ & $3.5 \pm 0.2$ & -98 \\
\hline
\end{tabular}

histograms displaying particle size distribution are shown in the right panels: $\mathbf{f}$ and $\mathbf{g}$ are high-resolution images for $\mathrm{Au}-\mathrm{TC}$ and $\mathrm{Au}-$ CYS, respectively

sizes bigger than the maximum, which could mask the influence of capping on the hydrodynamic diameter. DLS distribution is slightly wider than TEM distributions (with a higher size dispersion) which can explain the influence of capping on hydrodynamic size. We obtained similar results for Au-GSH NPs. Other authors also find this correlation between TEM and DLS sizes, indicating that we work at the detection limit for the DLS instrument and thus small NPs with very low scattering are less detected. In the case of Au-C NPs, DLS sizes are considerably smaller than the corresponding TEM sizes, probably due to a higher size dispersion, that cause a lower precision in the average values obtained from both methods.

In all cases, we obtained Au NPs with high stability in aqueous colloidal solutions.

$Z$ potential values obtained for each type of Au NP as prepared are also shown in Table $1 . Z$ potential values are high for all NPs, pointing out to their high stability in water colloidal solution and, consequently, to their suitable features for biomedical applications. These measurements shed information on the NP surface charge sign that can be relevant for subsequent cross-linking applications. All NPs show negative values for $Z$ potential, except Au-CYS NPs, probably due to the protonation of its amino terminal groups (see Fig. 1b). 
The functional groups in the samples were analyzed using FT-IR measurements, with the objective to analyze differences between Au NPs capped with different ligands. Figure 3a shows FT-IR spectra obtained for the four types of Au NPs. All NPs show similar spectra with the main bands in the same positions. The broadest peak around $3467 \mathrm{~cm}^{-1}$ can be attributed to stretching $\mathrm{O}-\mathrm{H}$ vibration, and the band at $1638 \mathrm{~cm}^{-1}$ is frequently attributed to $\mathrm{C}-\mathrm{H}$ stretch. All the spectra show a peak at $675 \mathrm{~cm}^{-1}$ corroborating the presence of Au NPs. When we amplify the region between 1500 and $900 \mathrm{~cm}^{-1}$ (Fig. 3b), we can appreciate some differences.
As expected, Au-C and Au-TC, NPs with the same chemical surround, show the same profile, with no significate differences in the peak positions. Au-GSH and $\mathrm{Au}-\mathrm{CYS}$ show a peak at $1030 \mathrm{~cm}^{-1}$ that could be assigned to C-S stretching vibrations. Au-GSH shows two more peaks, one at $1412 \mathrm{~cm}^{-1}$, assigned to asymmetric stretching vibration of carboxylate groups (COO-), and another at $1314 \mathrm{~cm}^{-1}$, associated with stretching vibration of the $\mathrm{C}-\mathrm{N}$ of amide. Finally, in the case of Au-CYS, the peak at $1360 \mathrm{~cm}^{-1}$ can be associated with C-N stretching coupled with N-H deformation (Anand et al. 2017; Mathialagan and Shanmugam 2018).
Fig. 3 a FTIR spectra for the different Au NPs. b Amplification of the region between wavenumber 1500 and $900 \mathrm{~cm}^{-1}$
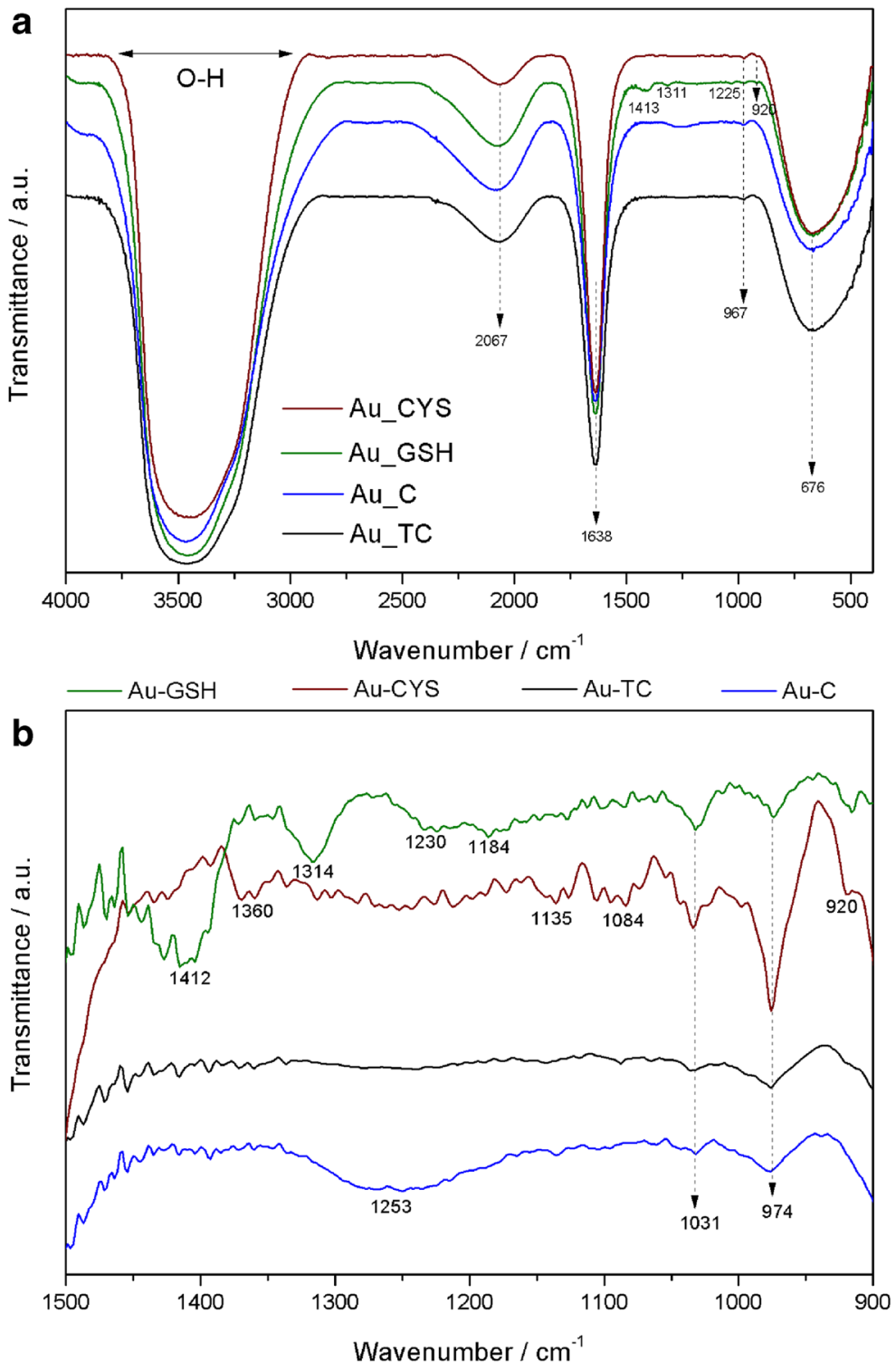
Optical behavior

\section{UV-visible absorption}

The presence of gold NPs in the obtained colloidal solutions has also been confirmed by UV-visible absorption. Position and width of LSPR bands give information about NP size and homogeneity. Figure 4a shows the UV-Vis absorption spectra for the different Au NP colloids. Wavelength values for LSPR bands are shown in Table 2. All NPs show the characteristic LSPR absorption band around $520 \mathrm{~nm}$, indicating the presence of small gold NPs. No significant differences are found for the position of the main absorption peak for different $\mathrm{Au}$ NPs. In the case of Au-C, a wide shoulder around $650 \mathrm{~nm}$, together with a general increase in absorption intensity in the range of $600-800 \mathrm{~nm}$, indicates the presence of bigger or non-spherical NPs. Interestingly, after centrifugation, this shoulder disappears, indicating that bigger NPs are eliminated with the centrifugation process.

The Au-GSH LSPR band shows a wider profile than that of the other colloids, which can be a consequence of the higher size dispersion in small NPs. The high number of surface atoms in small NPs, increases the damping of oscillating electrons at conduction bands. This effect can be even higher for small thiol capped NPs, due to the loss of itinerancy of electrons involve in Au-S bonding (Crespo et al. 2004; Fernandez et al. 2006).

NP diameters calculated from UV-Vis absorption spectra are also shown in Table 2. Haiss et al. proposed a method to estimate both NP size and particle number density, from absorption spectra for NPs smaller than
$30 \mathrm{~nm}$ (Haiss et al. 2007). This model takes into account the LSPR absorbance in relation to the typical Au absorbance at $450 \mathrm{~nm}$. They stablish a dependency between the logarithm of NP size and the ratio between the absorbance at the LSPR absorbance $\left(A_{\mathrm{LSPR}}\right)$ and the absorbance at $450 \mathrm{~nm}\left(A_{450}\right)$. Haiss et al. (2007) use the following expression to estimate NP size from UVVis spectra:

$d=\exp \left(B_{1} \frac{A_{S P R}}{A_{450}}-B_{2}\right)$

where $B_{1}$ (3.55) and $B_{2}(3.11)$ are the inverse of slope and intercept, respectively, obtained from the linear fit between the representation of the logarithm of NP size versus ratio $A_{\mathrm{SPR}} / A_{450}$.

Table 2 shows absorbance values at $450 \mathrm{~nm}$ and at the LSPR wavelengths for each NP size, as well as the UV-Vis sizes obtained from the Haiss method (Haiss et al. 2007). The TEM sizes have been included in order to facilitate comparison.

UV-Vis sizes obtained using the above equation (Table 2) are in general smaller than those obtained from TEM; however, they show the same general tendency. This UV-Vis method to calculate NP diameters, based in the difference between $\mathrm{Au}$ absorbance at $450 \mathrm{~nm}$ and LSPR Au band, considers only the smaller NPs that contribute to the main LSPR maximum band. In the case of TEM estimations, we also count bigger NPs, absorbing at higher wavelengths. Although both methods give the smallest diameter values for $\mathrm{Au}$ GSH NPs, the values obtained from the UV-Vis method for the Au-GSH NPs are particularly small. When we study the micrographs obtained from TEM for this NPs
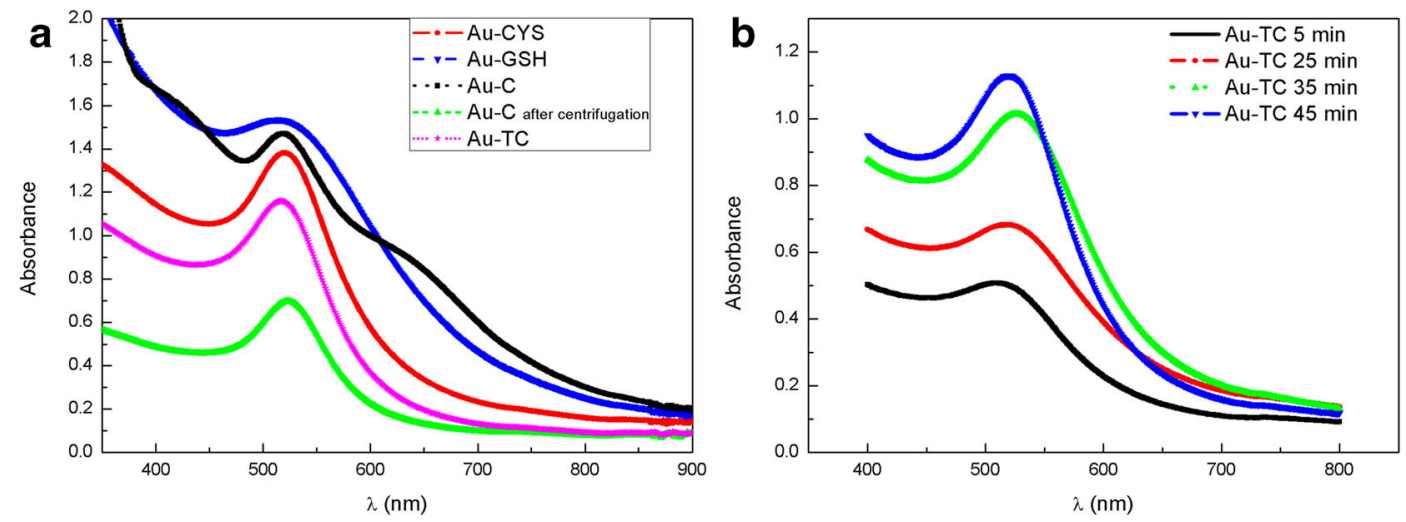

Fig. 4 UV-visible spectra for the four different Au NP solutions (a) and for Au-TC NPs during the growing process (b) 
Table 2 LSPR wavelength, absorbance values at $450 \mathrm{~nm}$ and at LSPR wavelength, and UV-Vis size estimates for different Au NPs

\begin{tabular}{lllllll}
\hline NP code & LSPR band position (nm) & $A_{\text {LSPR }}$ & $A_{450}$ & UV-Vis size (nm) & TEM size $(\mathrm{nm})$ & $N\left(\mathrm{NP}\right.$ number per cm $\left.{ }^{3}\right)$ \\
\hline Au-C & 520 & 0.86 & 0.60 & 9.2 & $14.5 \pm 0.28$ & $1.63 \times 10^{15}$ \\
Au-TC & 520 & 1.13 & 0.88 & 4.3 & $7.0 \pm 0.02$ & $1.25 \times 10^{15}$ \\
Au-CYS & 520 & 1.38 & 1.05 & 4.7 & $6.5 \pm 0.07$ & $1.80 \times 10^{15}$ \\
Au-GSH & 518 & 1.54 & 1.49 & 1.7 & $3.8 \pm 0.26$ & $3.72 \times 10^{15}$ \\
Au-TC 5 min & 508 & 0.51 & 0.46 & 2.5 & $3.6 \pm 0.03$ & $1.50 \times 10^{15}$ \\
\hline
\end{tabular}

(Fig. 2e), we can observe some NPs bigger than $3.5 \mathrm{~nm}$, which increases the average size. This proportion of bigger NPs is not included in the UV-Vis size estimation, according to the Haiss model.

These authors also propose a method to estimate the number density of NP. They propose analytical correlations between extinction efficiency and NP size, allowing an estimation of particle concentration (Haiss et al. 2007; Hendel et al. 2014; Tang et al. 2018). The values obtained from this estimation are also shown in Table 2.

Figure $4 \mathrm{~b}$ shows the temporal evolution of the UVVis absorption spectra for Au-TC NPs. At different time intervals during the synthesis $(5,25,35$, and $45 \mathrm{~min})$, aliquots of the colloidal solution were drawn and cooled, and the UV-Visible spectra measured. The LSPR band shifts from $508 \mathrm{~nm}$ after $5 \mathrm{~min}$ of reaction, to $520 \mathrm{~nm}$ at the end of the synthesis (45 min). As we have evaluated by TEM, small Au-TC nuclei are formed after 5 min of synthesis (Fig. 2b). Absorbance values at $450 \mathrm{~nm}$ and at the LSPR band have a relation with size and number of NPs in suspension. So, the LSPR for Au-TC at $5 \mathrm{~min}$ reaction is wider and centered at $508 \mathrm{~nm}$ as we have small NPs, but as the reaction progresses, the number of nuclei saturates and they grow due to Ostwald ripening, leading to a narrower band at $520 \mathrm{~nm}$. The interest of this method resides in the fact that small NPs (nuclei obtained at the first step of reaction) with high size homogeneity and capped with citrate molecules can be obtained. When we compare size values obtained from TEM and UV-Vis (Table 1), we can observe a very good agreement between both methods, pointing out to a higher size homogeneity for Au-TC after 5 min. AuGSH and Au-TC after 5 min show a similar TEM size. However, the UV-Vis size is considerably smaller for $\mathrm{Au}-\mathrm{GSH}$ NPs due to the presence of bigger NPs that are not taken into account in the UV-Vis estimations. Although Au-GSH and Au-TC at 5 min have a very similar size average, the size homogeneity is considerably higher in the case of Au-TC. This seeded-growth method allows for the production of small NPs capped with citrate molecules, with a similar size than those obtained using GSH as capping agent.

In order to evaluate the $\mathrm{pH}$ range in which these functionalized NPs are stable, so we can select appropriate applications for each type of NP, we have studied the UV-Vis absorption at different $\mathrm{pH}$ values. Figure 5 shows UV-Vis absorption for the four different types of NPs in colloidal solutions at different $\mathrm{pHs}$.

NPs capped with citrate molecules, $\mathrm{Au}-\mathrm{C}$ and $\mathrm{Au}-$ TC, show a very good stability in the 6 to $11 \mathrm{pH}$ range. In this case, for acid $\mathrm{pH}$, the LSPR band becomes wider and the absorption in the $600-800 \mathrm{~nm}$ range increases, indicating aggregation of NPs. In the case of Au-CYS NPs, the absorption spectrum shows a narrow LSPR band at acid $\mathrm{pH}$ values, keeping a similar profile until $\mathrm{pH} 11$ is reached, after which, the spectrum starts to show evidences of $\mathrm{Np}$ aggregation. In the case of $\mathrm{Au}-$ GSH NPs, the absorbance spectrum shows a welldefined LSPR band in neutral and basic solutions, which slightly broadens at $\mathrm{pH} 3$, indicating the high stability of this type of NPs in a wide range of pH. Table S.1 in supplementary material shows $Z$ potential values obtained for NPs at different $\mathrm{pH}$. Summarizing, citrate capped NPs are more stable at neutral and slightly basic $\mathrm{pH}$, whereas the $\mathrm{pH}$ range of stability is widened for thiol capped NPs, mostly for Au-CYS NPs which show a high stability in acidic media. Interestingly, all NPs show relatively high stability at physiological $\mathrm{pH}$ values making them suitable for biomedical applications.

\section{PL emission}

Photoluminescent behavior of Au NPs can give information about the structure and influence of the ligands on metal cores. Moreover, this is an interesting property 

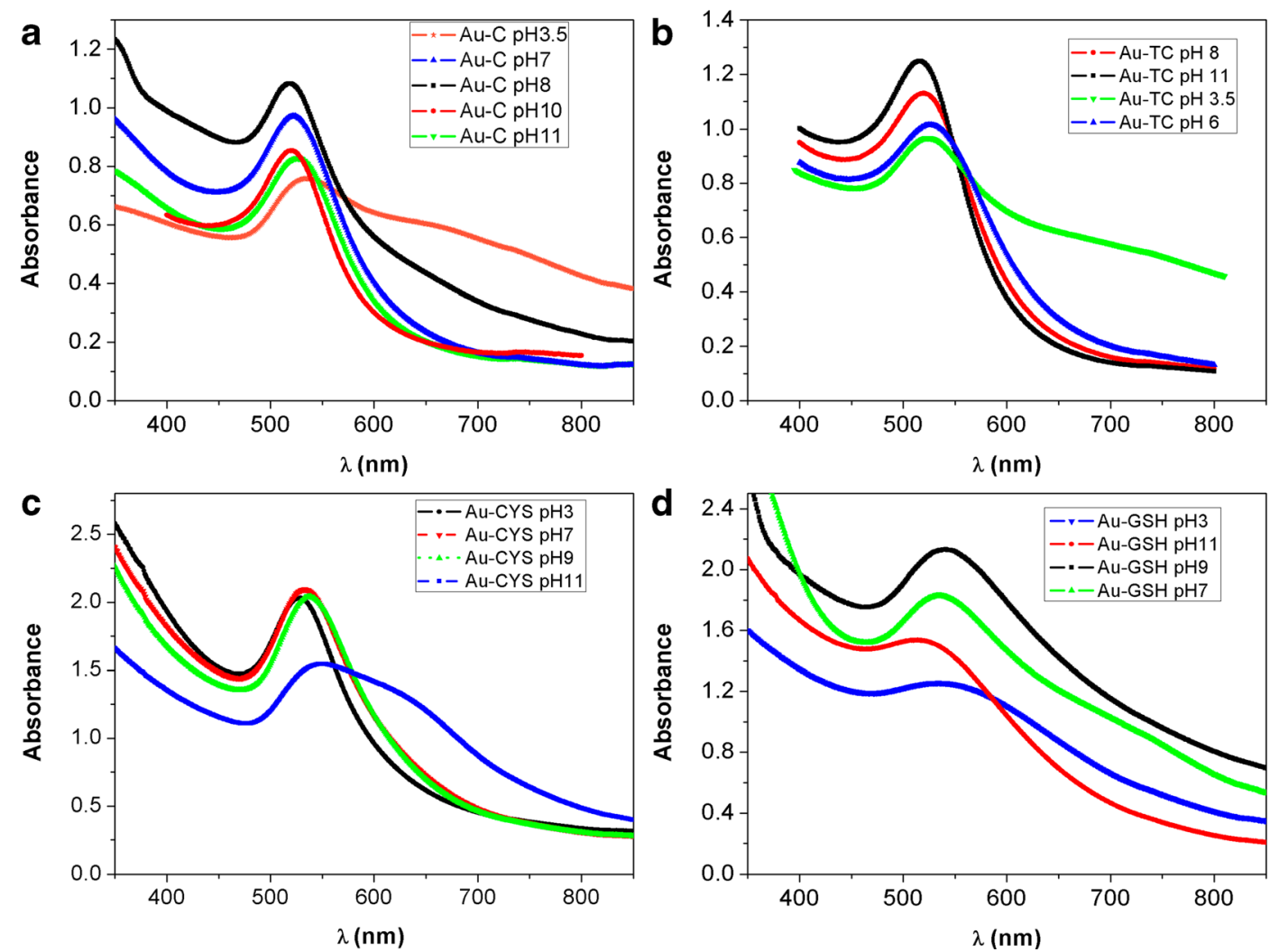

Fig. 5 Absorption spectra at different pH values for Au-C (a), Au-TC (b), Au-CYS (c), and Au-GSH (d) colloidal NP solutions

for the use of $\mathrm{Au}$ NPs as biomarkers. Figure 6a shows $\mathrm{PL}$ emission spectra recorded for the different Au NP colloidal solutions, exciting at $317 \mathrm{~nm}$. This excitation wavelength has been selected on the basis of the excitation spectra.

Samples Au-GSH, Au-TC, and Au-TC after a 5-min reaction show relatively strong emission bands in the blue range of the spectra. The emission is considerably lower for Au-CYS and Au-C. As we have previously mentioned, the origin of photoluminescence in gold NPs is still not clear and the emission band can be attributed to the interband transition $\mathrm{Au} 5 \mathrm{~d}^{10}$ to $6 \mathrm{sp}$ and also to the capping at the ligand-metal charge transfer transition. It has been previously reported that if the PL is due to the transitions in the metal core, the emission wavelength could be tunable, by increasing NP size, due to the quantum confinement effect (Chen et al. 2009). In our study, samples Au-TC (45 min reaction) and Au-TC after 5-min reaction have exactly the same capping ligand, being the average size, the only difference between them. However, the maximum wavelength for the emission bands are $428 \mathrm{~nm}$ for NPs with higher diameter (Au-TC) and $435 \mathrm{~nm}$ for NPs with lower diameter (Au-TC after $5 \mathrm{~min}$ ). There is no clear correlation between size and wavelength emission. Moreover, if we compare the emission of NPs with similar average size but different capping, samples Au-TC after a 5 min reaction and $\mathrm{Au}-\mathrm{GSH}$, we find that they show emission maxima at 435 and $416 \mathrm{~nm}$, respectively. This behavior seems to indicate that PL emission in these NPs is not mainly determined by the metal core transitions, suggesting the influence of capping-core transferences. However, Au-C NPs also capped with citric acid show a very weak emission. Au-C NPs have a considerably bigger size dispersion than Au-TC NPs. Although both types of NPs are capped with citrate ligand, the capping is much more effective in the case of Au-TC, in which, due to the high size homogeneity, approximately the same number of citrate molecules surrounds the gold core in all NPs, enhancing the intensity of PL emission. This capping is still more efficient in the case of NPs linked to GSH molecules (Au-GSH NPs) due to the 

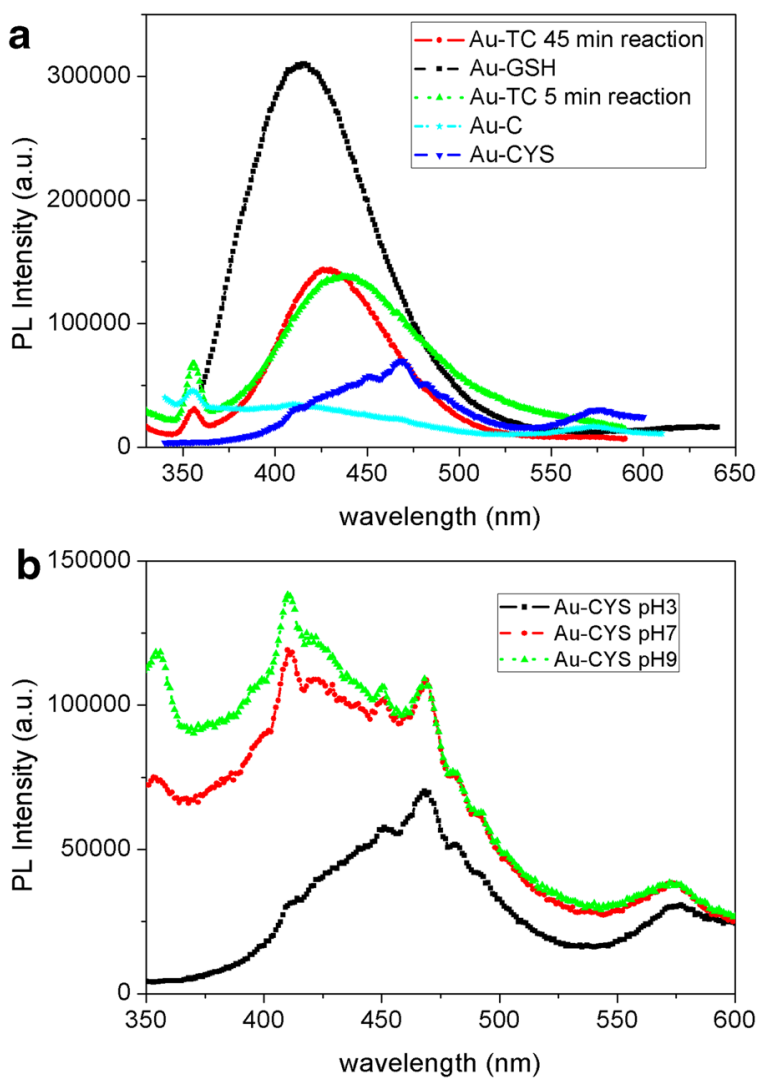

Fig. 6 PL emission spectra for Au NP solutions excited at $317 \mathrm{~nm}$ (a). PL emission spectra for Au-CYS NP colloidal solutions at different $\mathrm{pH}$ values (b)

strong donor character of the thiol group present in GSH molecules. The PL emission in the case of Au-CYS NPs is considerably weaker than that of Au-GSH, in spite of the thiol group also linked to the core surface. Considering the small average size of Au-GSH NPs, and our previous results demonstrating that a high proportion of GSH molecules are linked to NP cores of approximately 3-nm diameter, we hypothesize a strong influence of the thiol capping in these NPs. Au-CYS NPs have a higher average size and consequently less ligand-core transference contributing to the PL. We also have to consider that we have a smaller number of NPs per volume in the case of Au-CYS (Table 2). Moreover, their poor emission can also be a consequence of the influence of $\mathrm{pH}$. The colloidal solution resulting from this synthesis has an acid $\mathrm{pH}$ (Au-CYS colloid has acid $\mathrm{pH}$ as prepared). Sun's work demonstrated that the $\mathrm{Au}^{3+}$ has a higher tendency to be reduced at basic $\mathrm{pH}$ (Sun et al. 2011). Moreover, Liu et al. (Liu et al. 2014) find considerably higher QY values for gold NPs synthetized at $\mathrm{pH} 9$. Figure $6 \mathrm{~b}$ shows the PL emission spectra obtained for $\mathrm{Au}-\mathrm{CYS}$ as prepared $(\mathrm{pH} 3)$ and at different $\mathrm{pH}$ values. The emission increases from acid to basic $\mathrm{pH}$ values, reaching the maximum intensity at $\mathrm{pH} 9$. As $\mathrm{pH}$ changes from 3 to 6 , a first peak around $416 \mathrm{~nm}$ appears. The gold nanoparticles are more stable in neutral and basic $\mathrm{pH}$ range. Even though the Au NPs are functionalized with CYS, when moving towards acidic medium, the increasing number of protons in solution can affect the $\mathrm{Au}-\mathrm{S}$ bond, which can eventually lead to aggregation and a size increase for gold nanoparticles. The noisy emission band profiles suggest the presence of surface processes contributing to the fluorescence. The surface defects originated by the acid synthesis can lead to nonradiative processes, decreasing the PL emission of these NPs, in spite of the influence of the strong donor ligand. All these evidences, together with the high stoke's shift (more than $100 \mathrm{~nm}$ ), suggest a strong influence of NP surface in its PL behavior, mainly governed by ligandmetal transference transitions and by surface processes (Chen et al. 2009; Liu et al. 2014).

Results obtained from PL dynamic experiments for the NPs with higher emissions (Au-GSH and $\mathrm{Au}-\mathrm{TC}$ ) reveal the existence of two processes contributing to the fluorescence, since PL decays can be fitted to a biexponential curve. Table 3 shows PL lifetime constants, $\tau_{1}$ and $\tau_{2}$, as well as pre-exponential parameters, $A_{1}$ and $A_{2}$, obtained from the fitting. In all cases, there is a process characterized by the lifetime constant $\tau_{1}$ ranging between 12.7 and $17.6 \mathrm{~ns}$, and a second process slightly faster than the first one, with a life constant, $\tau_{2}$, around 3 ns (Table 3). The low QY obtained for many authors in metal NPs has the origin in the existence of non-radiative processes. The fastest process found for our NPs, probably related to surface and mainly nonradiative transitions, has in all cases a higher weight than the slower one, which is probably associated with ligand-metal radiative transferences.

Table 3 Photoluminescence lifetime constants and QY values for $\mathrm{Au}-\mathrm{TC}$ and Au-GSH NPs

\begin{tabular}{lllcrl}
\hline Sample & $\tau_{1}(\mathrm{~ns})$ & $\tau_{2}(\mathrm{~ns})$ & $A_{1}$ & $A_{2}$ & QY $(\%)$ \\
\hline Au-TC & 15.5 & 3.5 & 16 & 284 & 0.9 \\
Au-TC 5 min & 17.6 & 3.0 & 153 & 2279 & 1.2 \\
Au-GSH & 12.7 & 2.6 & 23.5 & 1213 & 2.1 \\
\hline
\end{tabular}


We have estimated QY of the NPs with higher emissions, Au-GSH and Au-TC, using quinine sulfate (56\%) as standard (Table 3). The obtained QY values are relatively high compared with values traditionally find for gold NPs. The capping effect, and consequently the charge transfer between electron donor ligand and metal core in these NPs, enhances the radiative processes increasing the QY, an indication that these two types of Au NPs are candidates for imaging studies.

\section{Intracellular staining}

We wanted to analyze whether the blue emission observed in Fig. 6 could be detected in cells by means of fluorescence microscopy, an application broadly used in Biomedicine. As shown in Fig. 7, cells cultured in the presence of NP-C, NP-GSH and NP-TC, have an increased blue fluorescence when compared to cells cultured in the absence of NP, although such difference is only statistically significant $(p<0.01)$ for NP-TC (Fig. 7). This results are in agreement with the highest PL emission observed for NP-TC nanoparticles and indicate that they not only emit blue fluorescence but can also enter cells. On the other hand, NP-CYS cultured cells showed a fluorescence higher than the one granted by its PL emission, probably due to the fact that their positive charged surface favors cellular uptake (Goodman et al. 2004); conversely, NP-GSH cultured cells show a lower emission than expected by the PL studies, probably due to the increased toxicity that selects cells that have incorporated less NPs. Uptake of particles of the size prepared in our experiments relies on active energy-dependent mechanisms that include dynamin-dependent (both clathrin and caveolin) mediated endocytosis (Ding et al. 2018), while larger or aggregated particles may mainly go through, by macropinocytosis (Gao et al. 2005). As the size and composition of the core $\mathrm{Np}$ are fairly similar, the differences seen in our experiments between NP very likely stem from differences in the corona (Cheng et al. 2015; Ding et al. 2018).

\section{Biocompatibility of NPs}

\section{Effect of NPs on cell viability}

In order to analyze biocompatibility of the QD solutions developed, we analyzed their effect on cell toxicity, not only in a tumor cell line such as Jurkat, frequently used as a model for lymphocytes, but also directly in primary cells that more closely mimic the real situation in which NPs will eventually be used in clinical settings. Analysis in primary cells is relevant as tumor cells frequently have different sensitivities to lysis than their primary counterparts. As primary cells, we have chosen PHA blasts from PBMC as a representation of cells present in the blood. When extracted, they are composed mainly of lymphocytes

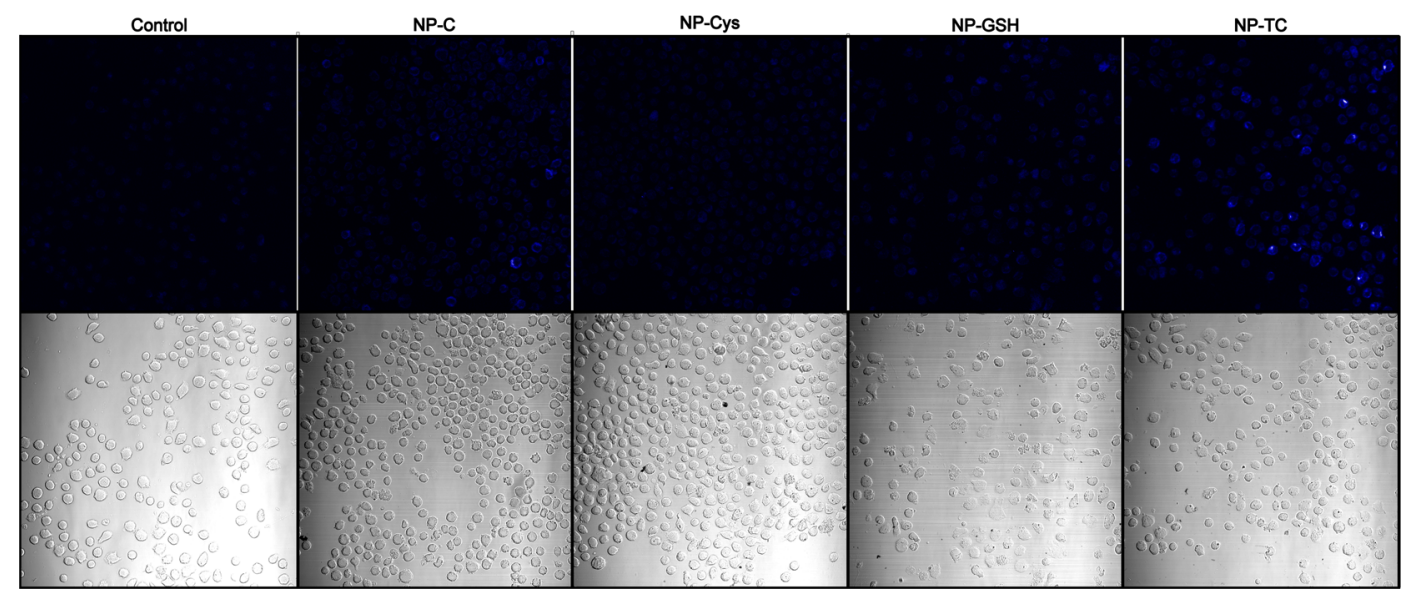

Fig. 7 Fluorescence microscopy images of cells that were incubated with different NPs (Au-C, Au-Cys, Au-GSH, or Au-TC) or cultured in the absence of NPs as a control. The corresponding transmitted light microscopy images are shown in the lower panel. Images from three different experiments were analyzed and both total and positive cells were counted with the aid of FIJIß software. The percentage of fluorescent cells from three different experiments was analyzed for statistical significance by ANOVA (only NP-TC shows a statistically significant increase in fluorescence above control cells $[p<0.01]$ ) 
Fig. 8 MTT cell viability assay of primary lymphocytes (upper panels) or Jurkat tumor cells (lower panels), incubated with the indicated NPs at $15 \mu \mathrm{g} / \mathrm{mL}$ (left panels) or $1.5 \mu \mathrm{g} / \mathrm{mL}$ (right panels). Results are represented as the mean \pm standard deviation of at least three independent experiments performed in triplicate. Statistical analysis was performed using the GraphPad Prism 5.00 software. Significance was determined using a $t$ test. Statistical significance is indicated by an asterisk $(* p<0.05)$
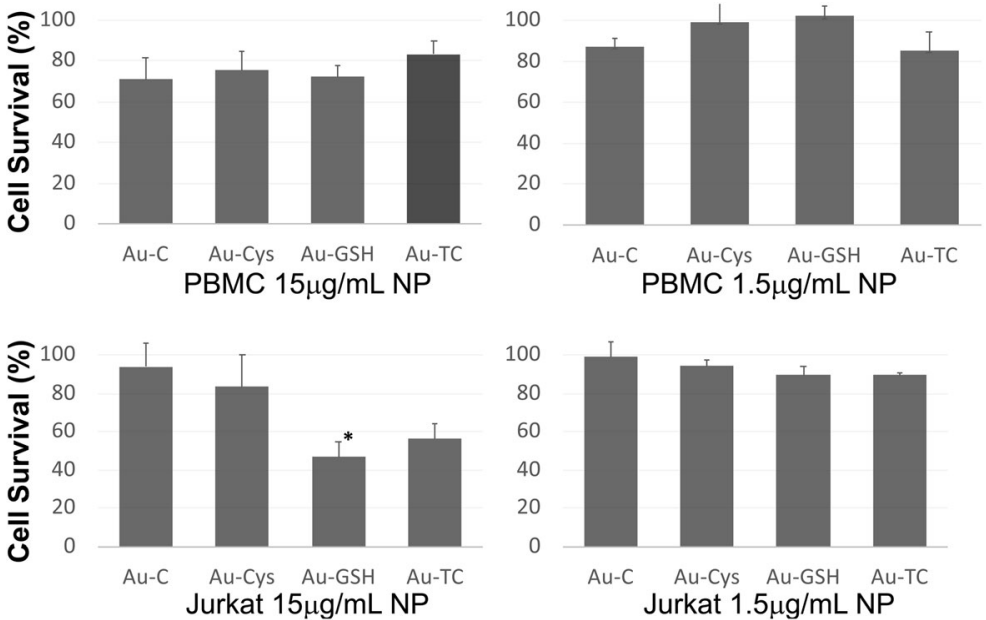

(both $\mathrm{T}$ and $\mathrm{B}$ cells) as well as monocytes. The one used in the toxicity experiments was activated for 6 days (with a mitogen that resembles antigen stimulation), causing them to physiologically proliferate (or "blast"). This blasts react more readily to stimuli or toxic substances than their resting counterparts and thus, are more suitable for cytotoxic studies. The mitogen used activates only T cells; thus, after 6 days, only $\mathrm{T}$ cells remain (see staining in supplementary Fig. S.1). JKT cells have been selected, as it is a tumor cell line widely used as a $\mathrm{T}$ cell model for signal transduction and toxicity experiments; this way, we could compare primary cells that are proliferating physiologically vs tumor cells that are proliferating because they are tumors.

We analyzed cell viability by MTT assay, as shown in Fig. 8; primary cells cultured in the presence of NPs at a very high concentration $(15 \mu \mathrm{g} / \mathrm{mL})$ showed a cell viability from 70 to $80 \%(71 \pm 11 \%, 75 \pm 9 \%, 72 \pm 6 \%$, and $83 \pm 7 \%$ for $\mathrm{Au}-\mathrm{C}$, Au-CYS, Au-GSH, and $\mathrm{Au}-\mathrm{TC}$, respectively), while with the concentrations commonly used for this type of experiments in the literature $(1.5 \mu \mathrm{g} / \mathrm{mL})$, cell viability was close to $100 \%(87 \pm$ $4 \%, 99 \pm 15 \%, 102 \pm 5 \%$, and $85 \pm 10 \%$ for $\mathrm{Au}-\mathrm{C}$, Au$\mathrm{CYS}, \mathrm{Au}-\mathrm{GSH}$, and $\mathrm{Au}-\mathrm{TC}$, respectively). Interestingly, when Jurkat tumor cells were analyzed, there is a significant effect of Au-GSH in cell viability (only $49 \pm 5 \%$ of viable cells) and some effect for Au-TC (52 $\pm 9 \%)$, while the other NPs show viability profiles similar to that of primary cells $(89 \pm 10$ and $72 \pm 5$ for $\mathrm{Au}-\mathrm{C}$ and $\mathrm{Au}-\mathrm{CYS}$, respectively); again with NPs at $1.5 \mu \mathrm{g} / \mathrm{mL}$, cell viability was close to $100 \%(99 \pm 8 \%, 94 \pm 3 \%, 89$ $\pm 4 \%$, and $89 \pm 1 \%$ for $\mathrm{Au}-\mathrm{C}, \mathrm{Au}-\mathrm{CYS}, \mathrm{Au}-\mathrm{GSH}$, and $\mathrm{Au}-\mathrm{TC}$, respectively).

\section{Effect of NPs on cytotoxicity}

As the MTT assay measures the number of viable cells (those capable of transforming the MTT substrate) and such number depends not only on cells that have not died (and thus indirectly measures cytotoxicity) but also depends on proliferation, we used a state-of-theart method to directly evaluate cell death, using flow cytometry, that directly gives a statistical evaluation of cell populations using a fluorescent dye that specifically stain dead cells, with excitation and emission features that are completely different from those of the NPs tested, thus preventing any overlapping in the detection.

As shown in the upper panel of Fig. 9, the percentage of dead primary lymphocytes (PBMC) in the presence of $15 \mu \mathrm{g} / \mathrm{mL}$ NPs was low for AU-C (2.46\%), Au-CYS (2.35\%), and $\mathrm{Au}-\mathrm{TC}(2.63 \%)$ and similar to that of control cells in the absence of NP (2.27\%), while it doubled for cells cultured in the presence of Au-GSH (4.65\%). Jurkat cells (Fig. 9, lower panels) also showed an increased toxicity in the presence of Au-GSH, but while ANOVA analysis showed that it was significant for PBMC $(p<0,002)$, it failed to do so for Jurkat cells, probably due to a higher variability in the results (no toxicity was observed at $1.5 \mu \mathrm{g} / \mathrm{mL}$ ). The difference observed between the number of viable cells in the MTT assay and the flow cytometry results stems partly from the fact that in the flow cytometry experiments, 


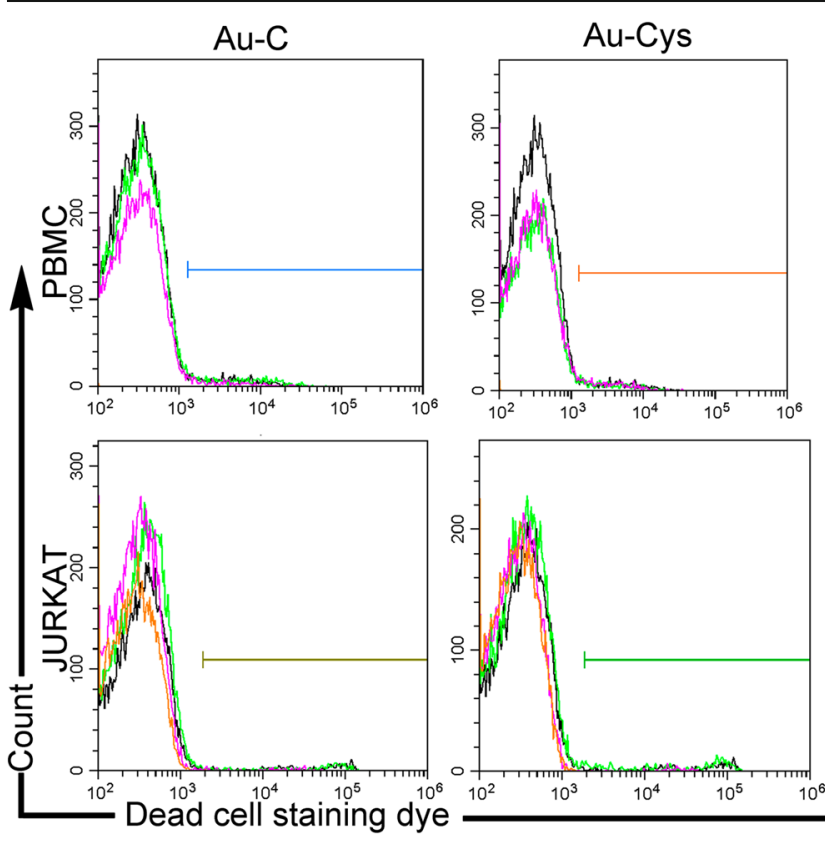

Fig. 9 Flow cytometry dot plot showing the cytotoxicity profile of primary lymphocytes - PBMC - (upper panels) or Jurkat tumor cells (lower panels), cultured with the indicated NPs. Cells (at least $10,000)$ were electronically gated according to their size/granularity distribution. Histograms corresponding to three Live/dead ${ }^{\mathrm{TM}}$ cell staining (dead cells) experiments are shown for

cells had been previously gated to select for the lymphocyte population and thus we are quantifying dead cells among a population that has not yet lost their size and granularity and has thus only recently initiated the dead path.

\section{Effect of NPs on cell proliferation}

As there was still some discrepancy between the viability and cytotoxicity assays, we wanted to determine whether a differential effect on proliferation could be responsible for the difference seen for the Au-GSH cultured Jurkat tumor cells. The most accurate method to analyze proliferation is by directly measuring DNA synthesis. Thus, we cultured Jurkat cells with EdU (5ethynyl-2'-deoxyuridine), a nucleoside analog to thymidine that is incorporated into DNA during active DNA synthesis and can be readily detected with a click reaction (Breinbauer and Kohn 2003), by means of a fluorescent dye. Thus, EdU at $10 \mu \mathrm{M}$ was added to Jurkat cells cultured in the presence or absence of NPs at $15 \mu \mathrm{g} / \mathrm{mL}$ to evaluate proliferation occurring after the addition of nanoparticles. As shown in Fig. 10a

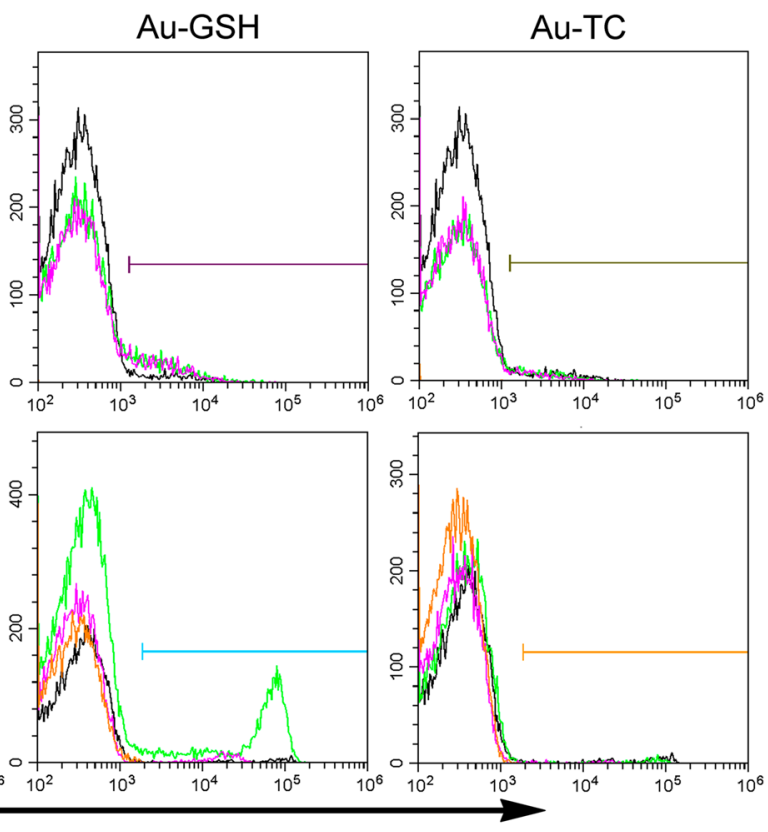

each Np. Within each histogram, different experiments for each $\mathrm{NP}$ are shown in different colors, with the control sample with no NP shown in black. According to a one-way ANOVA analysis (XLSTAT® Excell®), only PBMC cultured in the presence of AuGSH showed a significant increase in cell dead when compared to cells cultured in the absence of NPs $(p<0.002)$

(see also supplementary Fig. S.3 for individual histograms with percentages and supplementary Fig. S.4 for ungated populations), most positive control cells cultured in the absence of NP, as wells as cells cultured in the presence of NPs Au-C, Au-CYS, and Au-TC, have proliferated and thus incorporated Edu in their DNA $(87.51 \pm 6.17 \%$ in gate $\mathrm{P}$ for positive control cells and $89.64 \pm 3.77 \%, 87.20 \pm 3.01 \%$, and $88.65 \pm 3.57 \%$ in gate $\mathrm{P}$ for $\mathrm{Au}-\mathrm{C}, \mathrm{Au}-\mathrm{CYS}$, and $\mathrm{Au}-\mathrm{TC}$, respectively), while only $56.73 \pm 2.54 \%$ of cells cultured in the presence of Au-GSH have proliferated. Conversely, only $8.40 \pm 5.17 \%$ positive control cells cultured in the absence of NP are in gate "NP" for nonproliferating cells. Au-C, Au-CYS, and Au-TC show a similar percentage of non-proliferating cells $(6.67 \pm$ $3.34,6.77 \pm 2.43$, and $7.35 \pm 3.78$, respectively), while $30.17 \pm 8.40 \%$ of cells cultured in the presence of $\mathrm{Au}-$ GSH fall in the gate for non-proliferating cells, together with $98.54 \pm 0.73 \%$ negative control cells that have not incorporated Edu (Fig. 10b). Thus, Au-GSH developed in the present fashion shows a significant $(p<0.001)$ antiproliferative effect towards a percentage of tumor cells. 


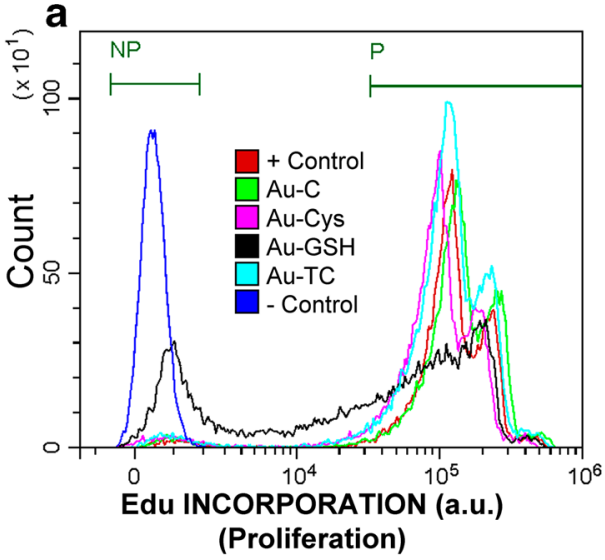

Fig. 10 Detection of proliferating cells by EdU incorporation and labeling. Jurkat tumor cells were cultured with $10 \mu \mathrm{M}$ EdU, in the presence or absence of the indicated nanoparticles at $15 \mu \mathrm{g} / \mathrm{mL}$. Proliferation was determined as a function of Edu incorporation into cells' DNA, detected by means of a Pacific blue fluorescent dye. EdU+ proliferating (gated in P) and non-proliferating cells (NP) were clearly and distinctly separated by FACS. Jurkat cells in the absence of NP were used as a positive control (+ control) for proliferation, as they are a tumor cell line that spontaneously

\section{Conclusions}

We have prepared highly soluble and stable sub$10 \mathrm{~nm} \mathrm{Au} \mathrm{NPs,} \mathrm{functionalized} \mathrm{with} \mathrm{different} \mathrm{cap-}$ ping agents. Citrate capped gold NPs (Au-C), prepared by the classical route, do not show the expected size homogeneity, being it necessary to include modifications in the synthesis to reach the high size mono-dispersion found for Au-TC NPs. Thiol capped gold NPs (Au-CYS and Au-GSH) show a homogeneous size distribution, with a particularly small average size for GSH capped NPs where a high proportion of GSH molecules are linked to each gold core. Citrate capped gold NPs show high colloidal stability at neutral and slightly basic $\mathrm{pH}$, being it possible to expand the stability range down to acidic $\mathrm{pH}$ for thiol capped NPs and particularly for Au-CYS NPs. All NPs have a negatively charged surface as prepared, except the Au-CYS, in which the terminal amine groups present in cysteamine, which provides a surface positive charge. These surface characteristics contribute to the poor PL emission of cysteamine capped NPs. However, AuTC and Au-GSH NPs show relatively intense blue PL emission, particularly in the GSH capped NPs, in

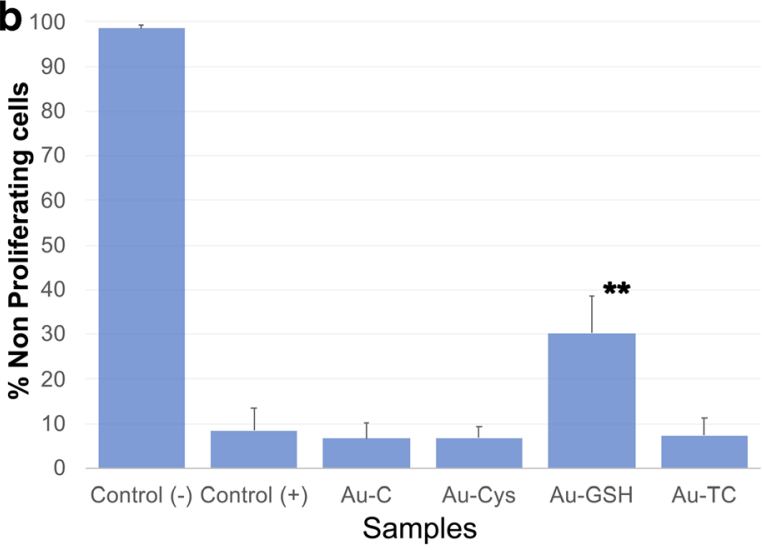

proliferate in culture. Cells that have not incorporated Edu were used as negative control ( - control). a Overlay histogram showing the proliferation profile of all samples. Samples had been electronically gated according to their size/granularity distribution. Individual samples as well as the gating strategy are shown in supplementary Fig. S.3. An overlay histogram of the ungated populations as well as results corresponding to individual ungated samples is shown in Fig. S.4.b) Average and standard errors for the percentage of non-proliferating cells under each condition $(* * p<0.001)$

which the thiol-metal core transference transitions considerably enhance the fluorescent emission; however, for cellular application, their higher toxicity makes them less suitable than NP-TC. The developed NPs show a high biocompatibility with low cytotoxicity even at high concentration. It is interesting to highlight that viability and toxicity profiles have been performed not only in tumor but also in primary cells. The inclusion of an assay that specifically measures proliferation also adds in the information on the biocompatibility profile of our NPs. On the other hand, the fact that Au-GSH NPs at high concentration show toxicity and inhibit proliferation of tumor cells opens an interesting avenue of research for additional applications that we will further pursue.

Acknowledgments We would like to thank the Core Biomedical Research Facility and the Core Science and Technology Research Facility of the University of Cadiz for the use of core infrastructure.

Funding information This work was supported by the Ministry of Education and Science, Instituto Nacional de Salud Carlos III (PI16-00784) and Iniciativa Territorial Integrada de la Junta de Andalucia (PI-0030-2017) for FGC. The funders had no role in 
study design, data collection and interpretation, or the decision to submit the work for publication.

\section{Compliance with ethical standards}

Conflict of interest The authors declare that they have no conflict of interest.

Open Access This article is distributed under the terms of the Creative Commons Attribution 4.0 International License (http:// creativecommons.org/licenses/by/4.0/), which permits unrestricted use, distribution, and reproduction in any medium, provided you give appropriate credit to the original author(s) and the source, provide a link to the Creative Commons license, and indicate if changes were made.

\section{References}

Albanese A, Tang PS, Chan WCW (2012) The effect of nanoparticle size, shape, and surface chemistry on biological systems. Annu Rev Biomed Eng 14(14):1-16. https://doi.org/10.1146 /annurev-bioeng-071811-150124

Anand K, Singh T, Madhumitha G, Phulukdaree A, Gengan RM, Chuturgoon AA (2017) Biosynthesis and computational analysis of amine-ended dual thiol ligand functionalized gold nanoparticles for conventional spectroscopy detection of melamine. J Photochem Photobiol B 169:75-82. https://doi. org/10.1016/j.jphotobiol.2017.02.019

Baetsen-Young AM, Vasher M, Matta LL, Colgan P, Alocilja EC, Day B (2018) Direct colorimetric detection of unamplified pathogen DNA by dextrin capped gold nanoparticles. Biosens Bioelectron 101:29-36. https://doi.org/10.1016/j. bios.2017.10.011

Bafrani HA, Ebrahimi M, Shouraki SB, Moshfegh AZ (2018) A facile approach for reducing the working voltage of $\mathrm{Au} / \mathrm{TiO} 2 /$ Au nanostructured memristors by enhancing the local electric field. Nanotechnology 29:015205. https://doi.org/10.1088 /1361-6528/aa99b7

Barman AK, Verma S (2010) Sunlight mediated disruption of peptide-based soft structures decorated with gold nanoparticles. Chem Commun 46:6992-6994. https://doi.org/10.1039 /c0cc02604b

Beato-Lopez JJ et al (2012) Preparation and characterization of fluorescent CdS quantum dots used for the direct detection of GST fusion proteins regular paper. Nanomater Nanotechno 2:10. https://doi.org/10.5772/53926

Beato-Lopez JJ et al (2017) CdTe quantum dots linked to glutathione as a bridge for protein crosslinking. J Lumin 187:193200. https://doi.org/10.1016/j.jlumin.2017.03.012

Bodelon G, Costas C, Perez-Juste J, Pastoriza-Santos I, LizMarzan LM (2017) Gold nanoparticles for regulation of cell function and behavior. Nano Today 13:40-60. https://doi. org/10.1016/j.nantod.2016.12.014
Breinbauer R, Kohn M (2003) Azide-alkyne coupling: a powerful reaction for bioconjugate chemistry. Chembiochem 4:11471149. https://doi.org/10.1002/cbic.200300705

Brust M, Walker M, Bethell D, Schiffrin DJ, Whyman R (1994) Synthesis of thiol-derivatized gold nanoparticles in a 2-phase liquid-liquid system. J Chem Soc Chem Commun 0:801802. https://doi.org/10.1039/c39940000801

Chen W, Tu X, Guo X (2009) Fluorescent gold nanoparticlesbased fluorescence sensor for $\mathrm{Cu} 2+$ ions. Chem Commun 7: 1736-1738. https://doi.org/10.1039/b820145e

Cheng X, Tian X, Wu A, Li J, Tian J, Chong Y, Chai Z, Zhao Y, Chen C, Ge C (2015) Protein corona influences cellular uptake of gold nanoparticles by phagocytic and nonphagocytic cells in a size-dependent manner. ACS Appl Mater Interfaces 7:20568-20575. https://doi.org/10.1021 /acsami.5b04290

Chithrani BD, Ghazani AA, Chan WCW (2006) Determining the size and shape dependence of gold nanoparticle uptake into mammalian cells. Nano Lett 6:662-668. https://doi. org/10.1021/n1052396o

Chuang H-S, Chen Y-J, Cheng H-P (2018) Enhanced diffusometric immunosensing with grafted gold nanoparticles for detection of diabetic retinopathy biomarker tumor necrosis factor-alpha. Biosens Bioelectron 101:75-83. https://doi.org/10.1016/j.bios.2017.10.002

Crespo P, Litrán R, Rojas TC, Multigner M, de la Fuente JM, Sánchez-López JC, García MA, Hernando A, Penadés S, Fernández A (2004) Permanent magnetism, magnetic anisotropy, and hysteresis of thiol-capped gold nanoparticles. Phys Rev Lett 93:087204. https://doi.org/10.1103 /PhysRevLett.93.087204

Dehn MH, Arseneau DJ, Buck T, Cortie DL, Fleming DG, King SR, MacFarlane WA, McDonagh AM, McFadden RML, Mitchell DRG, Kiefl RF (2018) Nature of magnetism in thiol-capped gold nanoparticles investigated with muon spin rotation. Appl Phys Lett 112:053105. https://doi.org/10.1063 /1.5017768

Ding L, Yao C, Yin X, Li C, Huang Y, Wu M, Wang B, Guo X, Wang Y, Wu M (2018) Size, shape, and protein corona determine cellular uptake and removal mechanisms of gold nanoparticles. Small e1801451. https://doi.org/10.1002 /smll.201801451

Dong W, Han J, Shi J, Liang W, Zhang Y, Dong C (2017) Amperometric biosensor for detection of phenolic compounds based on tyrosinase, N-acetyl-L-cysteine-capped gold nanoparticles and chitosan nanocomposite. Chin J Chem 35:13051310. https://doi.org/10.1002/cjoc.201600728

Dreaden EC, Alkilany AM, Huang X, Murphy CJ, El-Sayed MA (2012) The golden age: gold nanoparticles for biomedicine. Chem Soc Rev 41:2740-2779. https://doi.org/10.1039/c1 cs $15237 \mathrm{~h}$

Fernandez A, Sampedro B, Litran R, Rojas TC, Sanchez-Lopez JC (2006) Room temperature permanent magnetism in thiolcapped Pd-rich nanoparticles. Nanotechnology 17:14491453. https://doi.org/10.1088/0957-4484/17/5/047

Fratoddi I (2018) Hydrophobic and hydrophilic Au and Ag nanoparticles. Breakthroughs and Perspectives. Nanomaterials 8 . https://doi.org/10.3390/nano8010011

Gao H, Shi W, Freund LB (2005) Mechanics of receptor-mediated endocytosis. Proc Natl Acad Sci U S A 102:9469-9474. https://doi.org/10.1073/pnas.0503879102 
Ghosh P, Han G, De M, Kim CK, Rotello VM (2008) Gold nanoparticles in delivery applications. Adv Drug Deliv Rev 60:1307-1315. https://doi.org/10.1016/j.addr.2008.03.016

Giljohann DA, Seferos DS, Daniel WL, Massich MD, Patel PC, Mirkin CA (2010) Gold nanoparticles for biology and medicine. Angew Chem Int Ed 49:3280-3294. https://doi. org/10.1002/anie.200904359

Goodman CM, McCusker CD, Yilmaz T, Rotello VM (2004) Toxicity of gold nanoparticles functionalized with cationic and anionic side chains. Bioconjug Chem 15:897-900. https://doi.org/10.1021/bc049951i

Haes AJ, Zou SL, Schatz GC, Van Duyne RP (2004) A nanoscale optical biosensor: the long range distance dependence of the localized surface plasmon resonance of noble metal nanoparticles. J Phys Chem B 108:109-116. https://doi.org/10.1021 /jp0361327

Haiss W, Thanh NTK, Aveyard J, Fernig DG (2007) Determination of size and concentration of gold nanoparticles from UV-vis spectra. Anal Chem 79:4215-4221. https://doi.org/10.1021/ac0702084

Hendel T, Wuithschick M, Kettemann F, Birnbaum A, Rademann K, Polte J (2014) In situ determination of colloidal gold concentrations with UV-vis spectroscopy: limitations and perspectives. Anal Chem 86:11115-11124. https://doi. org/10.1021/ac502053s

Hu M, Chen J, Li ZY, Au L, Hartland GV, Li X, Marquez M, Xia Y (2006) Gold nanostructures: engineering their plasmonic properties for biomedical applications. Chem Soc Rev 35: 1084-1094. https://doi.org/10.1039/b517615h

Huang X, Neretina S, El-Sayed MA (2009) Gold nanorods: from synthesis and properties to biological and biomedical applications. Adv Mater 21:4880-4910. https://doi.org/10.1002 /adma.200802789

Huang Y, Liu Z, Gao G, Xiao Q, Martens W, du A, Sarina S, Guo C, Zhu H (2018) Visible light-driven selective hydrogenation of unsaturated aromatics in an aqueous solution by direct photocatalysis of Au nanoparticles. Cat Sci Technol 8:726734. https://doi.org/10.1039/c7cy02291c

Hutter E, Fendler JH (2004) Exploitation of localized surface plasmon resonance. Adv Mater 16:1685-1706. https://doi. org/10.1002/adma.200400271

Jain PK, Lee KS, El-Sayed IH, El-Sayed MA (2006) Calculated absorption and scattering properties of gold nanoparticles of different size, shape, and composition: applications in biological imaging and biomedicine. J Phys Chem B 110:72387248. https://doi.org/10.1021/jp057170o

Jain PK, Huang W, El-Sayed MA (2007) On the universal scaling behavior of the distance decay of plasmon coupling in metal nanoparticle pairs: a plasmon ruler equation. Nano Lett 7: 2080-2088. https://doi.org/10.1021/n1071008a

Jain PK, Huang X, El-Sayed IH, El-Sayed MA (2008) Noble metals on the nanoscale: optical and photothermal properties and some applications in imaging, sensing, biology, and medicine. Acc Chem Res 41:1578-1586. https://doi.org/10.1021/ar7002804

Kamyshny A, Magdassi S (2014) Conductive nanomaterials for printed electronics. Small 10:3515-3535. https://doi. org $/ 10.1002 / \mathrm{smll} .201303000$

Khan HA, Sakharkar MK, Nayak A, Kishore U, Khan A (2018) Nanoparticles for biomedical applications: an overview. Narayan, R(eds) Nanobiomaterials: Nanostructured materials for biomedical applications. Woodhead Publ Ltd, Abington
Hall Abington, Cambridge Cb1 6ah, Cambs, England, pp 357-384. https://doi.org/10.1016/b978-0-08-100716-7.00014-3

Khandanlou R, Murthy V, Saranath D, Damani H (2018) Synthesis and characterization of gold-conjugated Backhousia citriodora nanoparticles and their anticancer activity against MCF-7 breast and HepG2 liver cancer cell lines. J Mater Sci 53:3106-3118. https://doi.org/10.1007 /s10853-017-1756-4

Kim H, Lee JU, Song S, Kim S, Sim SJ (2018) A shape-code nanoplasmonic biosensor for multiplex detection of Alzheimer's disease biomarkers. Biosens Bioelectron 101: 96-102. https://doi.org/10.1016/j.bios.2017.10.018

Kobayashi Y, Shibuya K, Tokunaga M, Kubota Y, Oikawa T, Gonda K (2016) Preparation of high-concentration colloidal solution of silica-coated gold nanoparticles and their application to X-ray imaging. J Sol-Gel Sci Technol 78:82-90. https://doi.org/10.1007/s10971-015-3921-z

Lewinski N, Colvin V, Drezek R (2008) Cytotoxicity of nanoparticles. Small 4:26-49. https://doi.org/10.1002 /smll.200700595

Li Y, Xu Y, Fleischer CC, Huang J, Lin R, Yang L, Mao H (2018) Impact of anti-biofouling surface coatings on the properties of nanomaterials and their biomedical applications. J Mater Chem B 6:9-24. https://doi.org/10.1039/c7tb01695f

Liu B, Wang Y, Deng M, Lu J, Tong C, Lu C (2014) Blue light emitting gold nanoparticles functionalized with non-thiolate thermosensitive polymer ligand: optical properties, assemblies and application. RSC Adv 4:57245-57249. https://doi. org/10.1039/c4ra09335f

Mathialagan GD, Shanmugam N (2018) Hetero-functionalized gold nanoparticles to silence AU-rich element containing mRNAs in RAGE-expressing inflammatory cells: preparation, characterization, and in-vitro evaluation. J Nanosci Nanotechnol 18:3077-3086. https://doi.org/10.1166 /jnn.2018.14648

Miao Z, Gao Z, Chen R, Yu X, Su Z, Wei G (2018) Surfacebioengineered gold nanoparticles for biomedical applications. Curr Med Chem 25:1920-1944. https://doi. org/10.2174/0929867325666180117111404

Mooradian A (1969) Photoluminescence of metals. Phys Rev Lett 22:185. https://doi.org/10.1103/PhysRevLett.22.185

Nel AE, Mädler L, Velegol D, Xia T, Hoek EMV, Somasundaran P, Klaessig F, Castranova V, Thompson M (2009) Understanding biophysicochemical interactions at the nanobio interface. Nat Mater 8:543-557. https://doi.org/10.1038 /nmat 2442

Niidome T, Nakashima K, Takahashi H, Niidome Y (2004) Preparation of primary amine-modified gold nanoparticles and their transfection ability into cultivated cells. Chem Commun 1978-1979. https://doi.org/10.1039/b406189f

Pan Y, Neuss S, Leifert A, Fischler M, Wen F, Simon U, Schmid G, Brandau W, Jahnen-Dechent W (2007) Size-dependent cytotoxicity of gold nanoparticles. Small 3:1941-1949. https://doi.org/10.1002/smll.200700378

Peng C-F, Pan N, Qian Z-J, Wei X-L, Shao G (2017) Colorimetric detection of thiocyanate based on inhibiting the catalytic activity of cystine-capped core-shell Au@Pt nanocatalysts. Talanta 175:114-120. https://doi.org/10.1016/j. talanta.2017.06.005

Piella J, Bastus NG, Puntes V (2016) Size-controlled synthesis of sub-10-nanometer citrate-stabilized gold nanoparticles and 
related optical properties. Chem Mater 28:1066-1075. https://oi.org/10.1021/acs.chemmater.5b04406

Schindelin J, Arganda-Carreras I, Frise E, Kaynig V, Longair M, Pietzsch T, Preibisch S, Rueden C, Saalfeld S, Schmid B, Tinevez JY, White DJ, Hartenstein V, Eliceiri K, Tomancak P, Cardona A (2012) Fiji: an open-source platform for biological-image analysis. Nat Methods 9:676-682. https://doi.org/10.1038/nmeth.2019

Schneider CA, Rasband WS, Eliceiri KW (2012) NIH image to ImageJ: 25 years of image analysis. Nat Methods 9:671-675

Silvestri A, di Silvio D, Llarena I, Murray RA, Marelli M, Lay L, Polito L, Moya SE (2017) Influence of surface coating on the intracellular behaviour of gold nanoparticles: a fluorescence correlation spectroscopy study. Nanoscale 9:14730-14739. https://doi.org/10.1039/c7nr04640e

Sperling RA, Parak WJ (2010) Surface modification, functionalization and bioconjugation of colloidal inorganic nanoparticles. Philos Trans A Math Phys Eng Sci 368:13331383. https://doi.org/10.1098/rsta.2009.0273

Sugumaran S, Jamlos MF, Ahmad MN, Bellan CS, Schreurs D (2018) Nanostructured materials with plasmonic nanobiosensors for early cancer detection: a past and future prospect. Biosens Bioelectron 100:361-373. https://doi.org/10.1016/j. bios.2017.08.044

Sukhanova A, Bozrova S, Sokolov P, Berestovoy M, Karaulov A, Nabiev I (2018) Dependence of nanoparticle toxicity on their physical and chemical properties. Nanoscale Res Lett 13:44. https://doi.org/10.1186/s11671-018-2457-X

Sun C, Yang H, Yuan Y, Tian X, Wang L, Guo Y, Xu L, Lei J, Gao N, Anderson GJ, Liang XJ, Chen C, Zhao Y, Nie G (2011) Controlling assembly of paired gold clusters within apoferritin nanoreactor for in vivo kidney targeting and biomedical imaging. J Am Chem Soc 133:8617-8624. https://doi.org/10.1021/ja200746p

Tang J, Gao K, Ou Q, Fu X, Man S-Q, Guo J, Liu Y (2018) Calculation extinction cross sections and molar attenuation coefficient of small gold nanoparticles and experimental observation of their UV-vis spectral properties. Spectrochim
Acta A Mol Biomol Spectrosc 191:513-520. https://doi. org/10.1016/j.saa.2017.10.047

Turkevich J, Stevenson PC, Hillier J (1951) A study of the nucleation and growth processes in the synthesis of colloidal gold. Discuss Faraday Soc 11:55-75. https://doi.org/10.1039 /df9511100055

Verma A, Stellacci F (2010) Effect of surface properties on nanoparticle-cell interactions. Small 6:12-21. https://doi. org/10.1002/smll.200901158

Vistica DT, Skehan P, Scudiero D, Monks A, Pittman A, Boyd MR (1991) Tetrazolium-based assays for cellular viability: a critical examination of selected parameters affecting formazan production. Cancer Res 51:2515-2520

Wei Z-N, Yang X-X, Mo Z-H, Leng F (2018) Photocatalytic sensor of organics in water with signal of plasmonic swing. Sensors Actuators B Chem 255:3458-3463. https://doi. org/10.1016/j.snb.2017.09.176

Wilcoxon JP, Martin JE, Parsapour F, Wiedenman B, Kelley DF (1998) Photoluminescence from nanosize gold clusters. J Chem Phys 108:9137-9143. https://doi.org/10.1063 $/ 1.476360$

Wozniak A et al. (2017) Size and shape-dependent cytotoxicity profile of gold nanoparticles for biomedical applications. J Mater Sci Mater Med 28. https://doi.org/10.1007/s10856017-5902-y

Zhao L, Jiang D, Cai Y, Ji X, Xie R, Yang W (2012) Tuning the size of gold nanoparticles in the citrate reduction by chloride ions. Nanoscale 4:5071-5076. https://doi.org/10.1039/c2 $\mathrm{nr} 30957 \mathrm{~b}$

Zhu H, Ke X, Yang X, Sarina S, Liu H (2010) Reduction of nitroaromatic compounds on supported gold nanoparticles by visible and ultraviolet light. Angew Chem Int Ed 49: 9657-9661. https://doi.org/10.1002/anie.201003908

Zhu D-M, Xie W, Xiao YS, Suo M, Zan MH, Liao QQ, Hu XJ, Chen LB, Chen B, Wu WT, Ji LW, Huang HM, Guo SS, Zhao XZ, Liu QY, Liu W (2018) Erythrocyte membranecoated gold nanocages for targeted photothermal and chemical cancer therapy. Nanotechnology 29:084002. https://doi. org/10.1088/1361-6528/aa9ca1 